DR. NANCY MARGARET ENDERSBY-HARSHMAN (Orcid ID : 0000-0002-9834-4068)

DR. THOMAS LUDOVIC SCHMIDT (Orcid ID : 0000-0003-4695-075X)

4

5

6

7

8

9

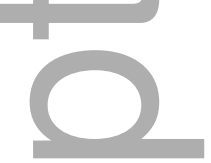

Article type : Original Article

\title{
Heterogeneous genetic invasions of three insecticide resistance mutations in Indo-Pacific
}

populations of Aedes aegypti (L.)

\section{Running title: Resistance by invasion in Indo-Pacific Ae. aegypti}

Nancy M. Endersby-Harshman ${ }^{1 * \bullet}$, Thomas L. Schmidt ${ }^{1 *}$, Jessica Chung ${ }^{1}$, Anthony van Rooyen ${ }^{2}$, Andrew R. Weeks ${ }^{1,2}$, Ary A. Hoffmann ${ }^{1}$

•corresponding author (nancye@unimelb.edu.au)

${ }^{1}$ Pest and Environmental Adaptation Research Group, School of BioSciences, Bio21 Institute, 30 Flemington Rd, Parkville, The University of Melbourne, Victoria 3010, Australia

${ }^{2}$ cesar Pty Ltd, 293 Royal Parade, Parkville Victoria 3052, Australia

\section{*Equal first authors}

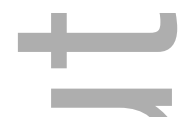

\section{Abstract}

Nations throughout the Indo-Pacific region use pyrethroid insecticides to control Aedes aegypti, the mosquito vector of dengue, often without knowledge of pyrethroid resistance status of the pest or origin of resistance. Two mutations (V1016G + F1534C) in the sodium channel gene (Vssc) of Ae.

This is the author manuscript accepted for publication and has undergone full peer review but has not been through the copyediting, typesetting, pagination and proofreading process, which may lead to differences between this version and the Version of Record. Please cite this article as doi: $10.1111 /$ MEC.15430

This article is protected by copyright. All rights reserved 
aegypti modify ion channel function and cause target-site resistance to pyrethroid insecticides, with a third mutation (S989P) having a potential additive effect. Of 27 possible genotypes involving these mutations, some allelic combinations are never seen while others predominate. Here, five allelic combinations common in Ae. aegypti from the Indo-Pacific region are described and their geographical distributions investigated using genome-wide SNP markers. We tested the hypothesis that resistance allele combinations evolved de novo in populations, versus the alternative that dispersal of Ae. aegypti between populations facilitated genetic invasions of allele combinations. We used latent factor mixed-models to detect SNPs throughout the genome that showed structuring in line with resistance allele combinations and compared variation at SNPs within the Vssc gene with genome-wide variation. Mixed-models detected an array of SNPs linked to resistance allele combinations, all located within or in close proximity to the Vssc gene. Variation at SNPs within the Vssc gene was structured by resistance profile, while genome-wide SNPs were structured by population. These results demonstrate that alleles near to resistance mutations have been transferred between populations via linked selection. This indicates that genetic invasions have contributed to the widespread occurrence of Vssc allele combinations in Ae. aegypti in the IndoPacific region, pointing to undocumented mosquito invasions between countries.

Key words: insecticide resistance, voltage sensitive sodium channel (Vssc), single nucleotide polymorphism (SNP), genetic invasion, linked selection, Aedes aegypti

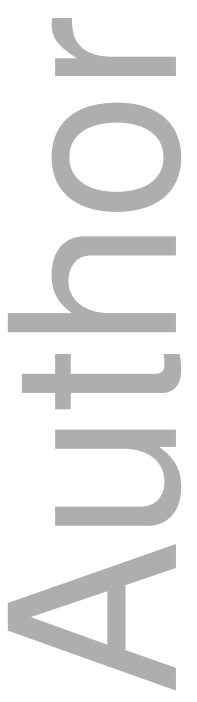




\section{Introduction}

Once an invertebrate pest species has invaded a new area, the ability to control the new incursion will depend on whether incursive populations are resistant to chemical pesticides available to control them. This in turn will depend on whether the incursive populations carry pesticide resistance alleles, which can arise through in situ evolution of resistance alleles and/or through the introduction of resistance alleles from other established populations. Both processes can be important in pest and disease vector control: examples of local evolution of resistance include pyrethroid resistance in the earth mite Halotydeus destructor (Yang et al., 2020) and organophosphate resistance in the whitefly Bemisia tabaci, while the long distance introduction of resistance genes is typified by pyrethroid resistance in the mosquito Culex pipiens (Chevillon, Raymond, Guillemaud, Lenormand, \& Pasteur, 1999); the contribution of both these factors in invading populations is highlighted by pesticide resistance in the spider mite Tetranychus urticae (Shi et al., 2019) and the moth Spodoptera frugiperda (Nagoshi et al., 2017).

Target-site or knockdown resistance ( $k d r)$ due to mutations in the sodium channel gene is one of the main mechanisms that compromises control of the dengue vector mosquito, Aedes aegypti, with pyrethroid insecticides (Smith, Kasai, \& Scott, 2016). These $k d r$ mutations have been detected widely in pest insects, following the first discovery of the L1014F mutation in the housefly, Musca domestica (Williamson, Denholm, Bell, \& Devonshire, 1993), which conferred resistance to DDT. The term ' $k d r$ ' now covers a range of mutations in different locations in the voltage-sensitive sodium channel (Vssc), with some being found across insect taxa and others being taxon-specific. To aid comparison of mutation sites between taxa, the numbering of codons is usually kept consistent with the codon numbers of the homologous region of the sodium channel gene of the housefly. Although multiple mutations (synonymous and non-synonymous) have been identified in the sodium channel of Ae. aegypti, only those non-synonymous mutations found in four positions (codons 1534, 1016, 1011 and 410) have been shown, in electrophysiological assays, to influence the function of the channel so that the toxic action of pyrethroid insecticides is diminished (Du et al., 2013; Haddi et al., 2017) (Figure 1).

Sodium channel mutations at codons 1016 and 1534 have been known for many years in Ae. aegypti and occur within the pyrethroid receptor sites in Domains II (S6) and III (S6) of the protein molecule 
(Du et al., 2013). These two mutations, V1016G and F1534C, are found in Ae. aegypti in the IndoPacific region (Figure 1). A third mutation, S989P, which is often in perfect linkage with V1016G, is not known to reduce the sensitivity of the sodium channel based on results of Du et al. (2013), but appears to confer some additive pyrethroid resistance in the homozygous state in combination with $1016 \mathrm{G}$ in Ae. aegypti from Yogyakarta, Indonesia (Wuliandari et al., 2015). S989P is also found in Ae. aegypti in the Indo-Pacific region. An additional mutation (D1794Y), which appears to have a similar effect to S989P when found in conjunction with V1016G, is known from Ae. aegypti in Taiwan (Chang, Huang, Chang, Wu, \& Dai, 2012; Chang et al., 2009; Lin, Tsen, Tien, \& Luo, 2013), and has not been shown to alter the sensitivity of the sodium channel to pyrethroids in electrophysiological assays (Du et al., 2013). A T1520I mutation found in Ae. aegypti from India is a third mutation which enhances resistance rather than affecting sodium channel sensitivity by itself and has been shown to increase resistance to Type I pyrethroids caused by F1534C (Chen et al., 2019).

Target-site resistance to pyrethroids is an autosomal, incompletely recessive trait controlled by a single gene (Chang et al., 2012) which has important implications for the resistance status of the heterozygote. Chang et al. (2012) expected the heterozygote at each site to show a level of tolerance to pyrethroid insecticides which is not much higher than that of wildtype (susceptible) individuals and this is the case for S989P+V1016G or F1534C in crossing experiments (Plernsub, Saingamsook, Yanola, Lumjuan, Tippawangkosol, Sukontason, et al., 2016). However, Plernsub et al. (2016) found some enhancement of resistance in the triple heterozygote (S989P/V1016G/F1534C) which showed resistance intermediate between a 1534C homozygous mutant strain and a 989P/1016G homozygous mutant strain in Thailand. Ishak et al. (2015) demonstrated a similar effect in the absence of S989P in Ae. aegypti in Malaysia and concluded that V1016G and F1534C heterozygotes occurring in the same individual have an additive effect on deltamethrin resistance of the mosquito.

Crosses performed by Plernsub et al. (2016) between a 1016GG/989PP and a 1534CC strain revealed that combinations of alleles are co-inherited. A haplotype donated by one parent maintains strong linkage patterns between the combination of the mutation sites. This linkage limits genotypes found in offspring of crosses and in the population in general. Several studies have noted that mutant homozygote $1016 \mathrm{G}$ is often found in conjunction with a wildtype homozygote at F1534 and vice versa (Ishak et al., 2015; Kawada et al., 2014; Stenhouse et al., 2013). Synthesis of data from these 
studies and our own observations suggest that certain haplotypes of the three mutation sites predominate in a population and there is little evidence of crossing over to disrupt the phase patterns found.

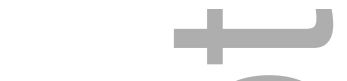

Management of $A e$, aegypti as a vector of dengue and other arboviruses requires knowledge of its insecticide resistance status and the likelihood of this status changing over time (Moyes et al., 2017; Plernsub, Saingamsook, Yanola, Lumjuan, Tippawangkosol, Walton, et al., 2016). Mosquito populations may become resistant to insecticides by local selection on new mutations or after the incursion of resistant genotypes into a new region which we refer to here as a "genetic invasion". Local selection pressures from insecticides are expected to vary due to different frequencies of application, rates and proportions of Type I and II pyrethroids applied, and in some cases, will select for specific genotypes, as was observed in Ae. aegypti from Yucatan State, Mexico (SaavedraRodriguez et al., 2015).

In the absence of strong local selection, resistance alleles are unlikely to increase in frequency in a population because their selective advantage will not be realised and they may carry a fitness cost (Brito et al., 2013). Vssc resistance alleles have not been detected in Ae. aegypti in northern Australia (Endersby-Harshman et al., 2017) suggesting that they are either not present or occur at very low frequency. If the latter case is correct, then the absence of local selection has prevented resistance alleles from increasing to a detectable frequency in this location. Resistance generated through local selection in one location may spread to others as mosquitoes disperse, resulting in the same resistance mutations occurring in unrelated populations.

Broad-scale geographic variation in the incidence of Vssc mutations occurs in Ae. aegypti; for example, in Southeast Asia the V1016G mutation is abundant, and in South America the V1016I mutation occurs at the same site; V1016G is clearly causative of pyrethroid resistance while V1016I alone has no effect on sodium channel sensitivity to pyrethroids, but has been shown to increase resistance to both Type I and II pyrethroids in conjunction with the F1534C mutation (Chen et al., 2019). At a local geographic scale, the occurrence and frequency of the 1016, 1534 and 989 mutations can also vary (Leong et al., 2019; C.-X. Li et al., 2015; Wuliandari et al., 2015; Yanola et al., 
2011). However, it is not clear if this variation reflects movement patterns of mosquitoes (genetic invasion) or ongoing mutation and selection. Evidence of resistance mutations spreading as mosquitoes move has been found in Ghana where mutation F1534C appeared, as a first record in Africa, associated with an intron phylogeny from Southeast Asia and South America (Kawada et al., 2016) (intron between exon 20 and 21 in the Vssc gene).

To resolve how broad-scale resistance patterns are produced, the distribution of resistance alleles can be compared to patterns of genetic differentiation in high resolution single nucleotide polymorphism (SNP) markers (Yang et al., 2020). As the recently developed genome assembly AaegL5 (Matthews et al., 2018) provides a precise genomic location for almost every SNP in Ae. aegypti, this methodology can be refined to compare patterns of genetic differentiation in SNPs close to the VssC gene with those of more distant SNPs. Genomic approaches using SNP markers have been effective at identifying differentiation in Ae. aegypti across a range of scales (J. E. Brown et al., 2014; GloriaSoria et al., 2018; Jasper, Schmidt, Ahmad, Sinkins, \& Hoffmann, 2019; Rašić, Filipović, Weeks, \& Hoffmann, 2014; Schmidt, Filipovic, Hoffmann, \& Rasic, 2018; Schmidt et al., 2019; Sherpa et al., 2017). The clear differentiation among Ae. aegypti populations (Rašić et al., 2014) provides a suitable background against which to compare differentiation at and around the Vssc gene region.

Here we report on the distribution of resistance alleles in Ae. aegypti from the Indo-Pacific region. We focus on those Vssc mutations found in Ae. aegypti from the Indo-Pacific region that have been shown in electrophysiological assays to reduce the sensitivity of the mosquito's sodium channel to pyrethroid insecticides (Du et al., 2013) as well as one mutation which has no effect on channel sensitivity, but may enhance resistance in association with one of the other mutations (Wuliandari et al., 2015). Oür study aims to (1) determine the geographical distribution of Vssc mutations at codons 989, 1016 and 1534 in Ae. aegypti from throughout the region; (2) compare genetic structure at sites near the Vssc gene with sites far from the Vssc gene; and (3) infer the possible processes leading to the Vssc distribution patterns found in mosquitoes throughout the Indo-Pacific. 
Samples of Ae. aegypti were collected from the field from 43 locations covering 11 countries in the Indo-Pacific region from April 2015 to February 2018 (Supplementary Table S1). Mosquitoes were collected as adults or larvae from water containers and, in the case of larvae, were reared to late instar stages or adults before being confirmed as Ae. aegypti, preserved and stored in either $>70 \%$ ethanol or RNAlater ${ }^{\circledR}$ (AMBION, Inc., Austin, Texas, USA).

DNA extraction

DNA was extracted from adult mosquitoes or late instar larvae using the DNeasy ${ }^{\circledR}$ Blood and Tissue kit (QIAGEN Sciences, Maryland, USA) according to the instructions of the manufacturer. Two final elutions of DNA were made with the first being used for construction of genomic libraries (see below) and the second being used for screening of Vssc mutations after being diluted 1:10 with water. 395 samples of Ae. aegypti from 11 countries were screened for Vssc mutations (Supplementary Table S1). The amino acid positions relating to the mutation sites in this study are labelled as S989P, V1016G and F1534C (Figure 1) according to the sequence of the most abundant splice variant of the house fly, Musca domestica, Vssc (GenBank accession nos. AAB47604 and AAB47605) (Kasai et al., 2014). These mutation sites are equivalent to those in other studies labelled as S996P, V1023G and F1565C based on the Vssc homologue in Ae. aegypti, the AaNav protein (GenBank accession no. EU399181) (Du et al., 2013). Custom TaqMan ${ }^{\circledR}$ SNP Genotyping Assays (Life Technologies, California, USA) were developed for each of the three target site mutations (Table 1) based on sequence information from Wuliandari et al. (2015).

Probes for the wildtype allele in each assay were labelled with Applied Biosystems ${ }^{\mathrm{TM}} \mathrm{VIC}^{\circledR}$ reporter dye in conjunction with a Minor Groove Binder (MGB) and a non-fluorescent quencher (NFQ). Probes

192 for the mutant allele were labelled with Applied Biosystems ${ }^{\mathrm{TM}} \mathrm{FAM}^{\mathrm{TM}}$ reporter dye, MGB and NFQ.

193 Three replicates of each $\operatorname{TaqMan}^{\circledR}$ assay were run on a LightCycler ${ }^{\circledR}$ || 480 (Roche, Basel, Switzerland) real time PCR machine in a 384-well format. The PCR Master Mix contained 40x TaqMan ${ }^{\circledR}$ assay as 
described above $(0.174 \mu \mathrm{L}), 2 x$ KAPA Fast PCR Probe Force qPCR Master Mix (KAPABIOSYSTEMS, Cape Town, South Africa) (3.5 $\mu \mathrm{L}), \mathrm{ddH}_{2} \mathrm{O}$ and genomic DNA as prepared above ( $\left.2 \mu \mathrm{L}\right)$. Conditions for the PCR run were pre-incubation of $3 \mathrm{~min}$ at $98^{\circ} \mathrm{C}\left(\right.$ ramp rate $4.8^{\circ} \mathrm{C} / \mathrm{s}$ ) followed by 40 cycles of amplification at $95^{\circ} \mathrm{C}$ for $10 \mathrm{~s}\left(2.5^{\circ} \mathrm{C} / \mathrm{s}\right.$ ramp rate) and $60^{\circ} \mathrm{C}$ for $20 \mathrm{~s}\left(2.5^{\circ} \mathrm{C} / \mathrm{s}\right.$ ramp rate) (Acquisition mode: single) with a final cooling step of $37^{\circ} \mathrm{C}$ for $1 \mathrm{~min}\left(2.5^{\circ} \mathrm{C} / \mathrm{s}\right.$ ramp rate). Endpoint genotyping was conducted using the Roche LightCycler ${ }^{\circledast} 480$ Software Version 1.5.1.62.
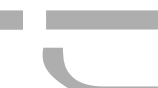

Testing for genetic invasions

Tests for genetic invasion were conducted on a single nucleotide polymorphisms (SNP) dataset comprising 80 of the Ae. aegypti screened for pyrethroid resistance. We investigated mosquitoes from ten countries, with eight individuals from each country included in the dataset. We considered individuals from the same country to be from the same population. For some populations, more than eight individuals were available for inclusion; in these cases, we first selected individuals for inclusion to preserve maximum variation in Vssc genotypes in that population (Figure 2), then selected them in order of having the least missing data. Removing excess individuals ensured that genetic differentiation measurements would not be biased by uneven population sample sizes. For large, genome-wide SNP datasets, five genotypes per population can be sufficient for estimating genetic differentiation (Willing, Dreyer, \& van Oosterhout, 2012). We omitted Vietnam from these analyses due to accidental loss of samples, and we also omitted populations lacking resistance mutations. Supplementary Table S2 gives details of the $80 \mathrm{Ae}$. aegypti used to test for genetic invasions. These include some individuals previously sequenced by Schmidt et al. (2019), that have been aligned to the AaegL5 genome assembly (Matthews et al., 2018) used in this study.

The 80 Ae. aegypti were genotyped for genome-wide SNPs using the double-digest RAD sequencing (ddRADseq) methodology of Rašić et al. (2014) and the bioinformatics pipeline Stacks v2.0 (Catchen, Hohenlohe, Bassham, Amores, \& Cresko, 2013). Reads were aligned to the AaegL5 genome assembly (Matthews et al., 2018) using Bowtie2 (Langmead \& Salzberg, 2012). The dataset was processed in Stacks and VCFtools (Danecek et al., 2011) with the following filters: SNPs must be biallelic, be present in $75 \%$ of mosquitoes in each population, have a minor allele count of $\geq 2$ (following Linck and Battey (2019)), have less than 5\% missing data, have read depth of between 3 and 45 (following (H. Li, 2014)), and have a known location on one of the three autosomes. The dataset was pre- 
filtered to ensure no putative first-order relatives were included (all Loiselle's $k<0.1875$; (Loiselle, Sork, Nason, \& Graham, 1995)). All library construction and filtering steps are detailed in the Supplementary Information S1.

We assigned mosquitoes with the A, C, D, and G genotypes to a resistance profile group "Profile GTC" (one or two copies of haplotype $\mathrm{H} 1$; Figure 2), assigned mosquitoes with the $\mathrm{B}, \mathrm{C}, \mathrm{E}$, and $\mathrm{H}$ genotypes to a second group "Profile TGT" (one or two copies of haplotype H2; Figure 2), assigned mosquitoes with the D, E, and F genotypes to a fourth group "Profile TTT" (one or two copies of haplotype H3; Figure 2), and assigned mosquitoes with the $\mathrm{G}$ and $\mathrm{H}$ genotypes to a third group "Profile GTT" (one or two copies of haplotype H4; Figure 2). Note the nomenclature refers to the mutations in order of degree of resistance conferred from highest to lowest, i.e. 1016/1534/989. Mosquitoes with the C, G, and $\mathrm{H}$ genotypes each had two of the above profiles.

To look for indications that resistance alleles have spread via genetic invasion, we investigated patterns of differentiation across the genomes of the 80 individuals. These analyses were motivated by the expectation that, if resistance alleles had been spread by genetic invasion, we would see different patterns of differentiation in SNPs around the VsSC gene than at other parts of the genome. Among populations in which a given resistance profile has become established via genetic invasion of a single de novo mutation, non-wildtype individuals with identical Vssc resistance profiles will have attained these profiles from the same invasive ancestors, and thus these individuals will have alleles that are identical by descent via this invasion. This shared identity by descent should be strongest among alleles at SNPs within and proximate to the Vssc gene region (chromosome 3; positions $315,926,360-316,405,638)$, and, specifically, to the point mutation conferring resistance for that profile. Considering the low recombination rate of Ae. aegypti (Bennett et al., 2005; S. E. Brown, Severson, Smith, \& Knudson, 2001), these patterns of linkage may remain even if gene flow ceased many generations ago or involved only a small number of invasive migrants.

Accordingly, if a given resistance profile had reached its present distribution in the Indo-Pacific region through genetic invasion from a single source population, we would expect to observe similar patterns of variation at SNPs within and proximate to the VsSC gene region for individuals with that 
resistance profile, even when they are from different populations. We would expect variation at other SNPs to be structured by population, as typically observed in Ae. aegypti (Rašić et al., 2014; Schmidt et al., 2019). In cases where a population has been recently genetically invaded, there may be very little differentiation in SNPs near the Vssc gene among individuals with that resistance profile. Overall, we would expect broad genetic similarity at the Vssc gene among all individuals sharing a resistance profile spread via genetic invasion, as alleles near the point mutation actively conferring resistance will be identical by descent. Clearly, analyses should not consider variation at the resistance point mutations themselves, which would confuse any comparison of identity by state and identity by descent. As ddRADseq targets only $1 \%$ of the genome, we considered it unlikely that any of the three resistance point mutations would be sequenced, and we checked to ensure that none of them were.

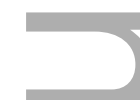

For a population in which resistance evolved independently, we would also expect to see broad similarities in genetic structure near the Vssc gene among individuals in that population sharing that resistance profile. However, while these individuals would have the same resistance mutation identical by state with individuals in other populations, the alleles near the Vssc gene would have no identity by descent across populations. Thus, if no genetic invasions have taken place, individuals with the same resistance profile would show structuring in SNPs near the Vssc gene along the same lines as SNPs elsewhere in the genome; that is, structuring by population of origin and not by resistance profile.

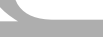

Wepertormedtwo ar

We performed two analyses to test for genetic invasions, both using the R package "LEA" (Frichot \& François, 2015). For the first analysis, we used sparse nonnegative matrix factorization (function $s n m f$ ) to investigate genome-wide patterns of genetic structure and determine an optimal number of clusters $(K)$ in which to partition the $80 \mathrm{Ae}$. aegypti genotypes. We then used the optimum $K$ to condition a latent factor mixed model (function Ifmm) (Frichot, Schoville, Bouchard, \& François, 2013), which scanned the genome for SNPs that were structured according to a set of environmental variables. For these variables, we used the two resistance profiles: GTC and TGT. We ignored Profile TTT for these analyses; although the susceptible, wild-type profile could serve as an interesting "null" against which to compare the other profiles, almost all of the individuals of Profile TTT were heterozygotes with haplotype $\mathrm{H} 2$ (Figure 2), thus preventing any unbiased comparison. Also, as 
Profile GTT was only found in a single population (Taiwan), it was not appropriate for inclusion in these analyses.

289

290

We ran snmf using 50 repetitions to determine the value of $K$ from 1 to 10 with minimum crossentropy, which was considered the best estimate of the number of ancestral populations. We ran Ifmm with 25 repetitions, using 10,000 iterations and 5,000 burn-in for each. The two resistance profiles were each treated as distinct variables and fit separately. In each case, z-scores were recalibrated using the genomic inflation factor (Frichot \& François, 2015).

For the second analysis of genetic invasion, we used the function pca to perform two principal components analyses (PCAs) on the 80 Ae. aegypti. The first PCA used only the SNPs that were located within the Vssc gene region. The second PCA used SNPs that were found anywhere outside the Vssc region. In the absence of genetic invasion, we would anticipate that both PCAs would partition the genetic variance roughly equivalently, along population lines. In the case of genetic invasion, we would expect the genetic variance of the Vssc SNPs to be structured by resistance profile and that of the non-Vssc SNPs by population.

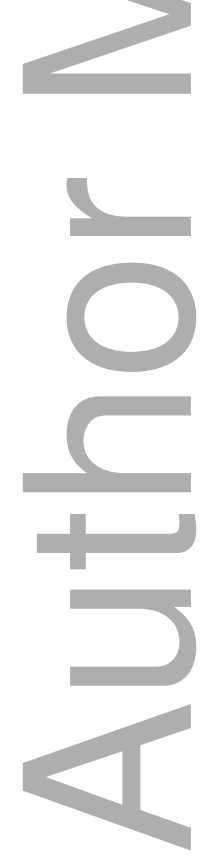

This article is protected by copyright. All rights reserved 
Variation was identified in the Vssc alleles and genotype combinations of Ae. aegypti throughout the Indo-Pacific region. Eight of the possible 27 combinations of genotypes of the three sodium channel mutation sites were identified in the samples of Ae. aegypti and five of these were present in high numbers (Table 2). Mutation sites 1016G and 989P were perfectly linked within our sample with respect to genetic state (except in a small number of individuals from Taiwan) and were in negative linkage disequilibrium with site 1534C. If we consider each possible state, namely wildtype homozygote, mutant homozygote and heterozygote, only three putative haplotypes are required to construct each of the observed combinations (excluding those from Taiwan) (Figure 2a). One additional haplotype is required to construct the two extra genotypes from Taiwan (Figure 2b).

Patterns of Vssc mutations were varied across the geographic dataset. From one to five mutation combinations (genotypes) were found at each geographic location with the most combinations (five) being identified from the remote Republic of Kiribati and from Taiwan (Table 2). Mosquitoes from Bali, Indonesia and the Republic of Vanuatu showed only one genotype pattern (homozygous mutant for 1016G and 989P, but wildtype for F1534 - designated as genotype A). Mosquitoes from Vietnam, New Caledonia and Fiji only showed mutations at the 1534 site (homozygous and heterozygous, genotypes $\mathrm{B}$ and $\mathrm{E}$ ) and the sample also contained some completely wildtype individuals (genotype F). Aedes aegypti from Singapore, Thailand and Malaysia showed three main genotype combinations, namely $A, B$ and $C(C=$ heterozygous at each of the three sites) (Figure 3 ).

Testing for genetic invasions

After filtering, we retained 50,569 genome-wide SNPs for genetic analyses, from an unfiltered set of 93,925 SNPs. Eighteen of these SNPs were located within the Vssc gene. Four of these SNPs were located within a VsSc exon region, of which three were in the $3^{\prime}$ untranslated region and one was in the coding region. None of the SNPs corresponded to any of the three point mutations conferring resistance. Mean depth across the filtered SNPs was 22.24 (s.d. 6.33) and mean missingness in individuals was $1.82 \%$ (s.d. $1.23 \%)$. 
Using the entire set of 50,569 SNPs, sparse nonnegative matrix factorization in LEA found $K=4$ to be the optimal choice for $K$ (Supplementary Figure S1). Latent factor mixed-models treating Profiles GTC and TGT as environmental factors found a set of SNPs strongly associated with each profile (Figure 4). These SNPs were all clustered around the $V s s c$ gene and had $-\log _{10}(P)$ of up to 57 , while elsewhere on the genome no SNP had $-\log _{10}(P)>15$. For Profile GTC, there were 26 SNPs of $-\log _{10}(P)>15$, all of which were found in a region 4,661,744 bp long (chromosome 3; positions 313,105,794 $317,767,538$ ) surrounding and containing the Vssc gene (chromosome 3; positions 315,926,360$316,405,638)$, with eight of these SNPs found within the Vssc gene. For Profile TGT, there were 23 SNPs of $-\log _{10}(P)>15$, which were found in a similar region 12,468,872 bp long (chromosome 3; positions $305,090,719-317,559,591$ ) containing the Vssc gene. Of these 23 SNPs, eight were located within the VSSC gene, which were the same eight SNPs detected as outliers in the latent factor mixedmodel for Profile GTC. Supplementary Figure S2 shows latent factor mixed-model results across a narrow band of chromosome 3 (positions 300,000,000 - 330,000,000).

PCA on the 18 SNPs within the Vssc gene region indicated that variation at these SNPs was much more clearly structured by resistance profile than by population (Figure $5 a, c, e$ ). When symbology of the PCA was used to indicate individuals of Profile GTC and those not of GTC (Figure 5a), Profile GTC individuals clustered to the top and to the left of most non-GTC individuals. Homozygous GTC individuals (dark blue squares) clustered more tightly and more distinctly than heterozygotes (light blue circles and triangles). A single non-GTC individual from Taiwan (white square) clustered with the 22 GTC homozygotes. Non-GTC individuals with a single copy of the haplotype H4 (green circles) clustered similarly to GTC individuals with a single copy of haplotype H1 (light blue circles and triangles), indicating a potential shared evolutionary origin of these haplotypes. This was also indicated by the single individual with a copy of each of the $\mathrm{H} 1$ and $\mathrm{H} 4$ haplotypes (light blue circle), which clustered with GTC homozygotes.

When symbology of the PCA was used to indicate individuals of Profile TGT and those not of TGT (Figure 5c), most Profile TGT individuals clustered to the top and to the right of most non-TGT individuals. As with Profile GTC, homozygotes (red squares) clustered more distinctly than heterozygotes (orange circles and triangles). Exceptions were the single Taiwanese homozygote that 
clustered with GTC homozygotes (white squares), and a Malaysian homozygote that clustered with TGT/wildtype heterozygotes (orange upside-down triangles) and wildtype homozygotes (white upside-down triangles) from New Caledonia.

When symbology of the PCA was used to indicate individuals by population (Figure 5e), no clear structuring was observed among the 18 Vssc SNPs. This was most apparent for populations containing a range of resistance profiles, such as Kiribati, Singapore, Sri Lanka, Thailand, and Taiwan. Individuals from these populations were distributed broadly across the PCA plot, indicating a lack of within-population similarity at the Vssc gene.

PCA on the 50,551 SNPs outside the Vssc gene presented the opposite pattern to that of the VssC gene (Figure $5 b, d$, $f$ ). Among these SNPs, genetic variation was structured unambiguously by population of origin (Figure 5f) and not by resistance profile (Figure $5 b, d$ ). The clustering of populations in Figure $5 \mathrm{f}$ reflects the $K=4$ estimated by sparse nonnegative matrix factorization, and shows population separation similar to that observed in previous studies (Schmidt et al., 2019). Clusters were: (1) New Caledonia and Vanuatu; (2) Fiji and Kiribati; (3) Taiwan; and (4) all remaining South and Southeast Asian populations.

Supplementary Figure S3 shows results of additional PCAs. For these, instead of using SNPs found within the Vssc gene and those not within the Vssc gene, we used SNPs with $-\log _{10}(P)>15$ associated with Profiles GTC and TGT by latent factor mixed-models (Figure 4). These showed very similar results to Figure 5 , wherein variation at $-\log _{10}(\mathrm{P})$ SNPs was structured by resistance profile (Supplementary Figure S3a, b) and not by population of origin (S2c, d).

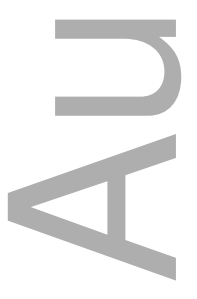

This article is protected by copyright. All rights reserved 


\section{Discussion}

This paper has outlined the geographical distributions of three sodium channel mutations found in Ae. aegypti from the Indo-Pacific and has presented evidence that these mutations have attained their present regional distributions via genetic invasion. This evidence relates to the genetic structure of SNPs at and around the Vssc gene, which showed that mosquitoes from different populations, but with the same resistance profiles, had similar patterns of variation in SNPs near the Vssc gene, compared with strong differentiation for the rest of the genome. These patterns indicate that the two widespread VsSC genotypes (mutations at codons 1016 and 1534, Profiles GTC and TGT respectively) have spread throughout the region by human transportation of mosquitoes. This addresses an important question about how target-site resistance arises in mosquito populations, which can occur through both genetic invasion and local de novo mutation. Our results indicate that strong linkage within the Vssc gene region restricts which of the 27 possible genotypes can be produced, which will help inform control strategies suited to local conditions, as resistance status varies greatly among these genotypes. In deriving these results, we also present a detailed geographical summary of pyrethroid resistance in the Indo-Pacific, a critically important region for dengue control.

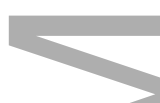

The negative linkage disequilibrium between Vssc mutations at codons 1016 and 1534 as well as the perfect linkage between mutation state at codons 1016 and 989 means that there was no possibility of finding an individual mosquito homozygous for all three mutations. The triple homozygous mutation (989P+1016G+1534C) has been found to enhance resistance to Type I and Type II pyrethroids to a very high level in Xenopus oocyte experiments when created artificially in the laboratory (Hirata et al., 2014). Hirata et al. (2014) caution that a single crossing over event could result in an individual with the triple mutation, however, this homozygous combination of mutations has been found only rarely in Ae. aegypti from the field (Ishak et al., 2015; Kawada et al., 2014; Sayono et al., 2016) in Penang, Malaysia; Myanmar and Surakarta, Indonesia and its resistance status in that context is not yet clear. Our proposal of inheritance by linked haplotypes with no recombination between mutation sites 1016 and 1534 may explain why the triple mutant does not often arise, even though a heterozygote $1016 / 1534 / 989$ is common. It is also possible that the triple mutant has a high fitness cost (Hirata et al., 2014; Plernsub, Saingamsook, Yanola, Lumjuan, Tippawangkosol, Sukontason, et al., 2016). A low number of Ae. aegypti collected from Saudi Arabia 
have been identified as being triple mutant heterozygotes with all three mutations on the same chromosome (unlike the combination of our haplotypes $\mathrm{H} 1$ and H2, Fig. 2a) and these individuals were susceptible to deltamethrin (Al Nazawi, Aqili, Alzahrani, McCall, \& Weetman, 2017).

In the absence of recombination, the presence of only three Vssc haplotypes $(H 1, H 2, H 3)$ explains why 21 of the 27 genotypes do not occur in the region (excluding Taiwan). The addition of a fourth haplotype $(\mathrm{H} 4)$ in the sample from Taiwan enables formation of the two extra genotypes ( $G$ and $H$, Fig 2) found there. If $\mathrm{H} 4$ were combined with $\mathrm{H} 3$, another of the 27 possible genotypes could be constructed, but individuals of this genotype (TG/TT/TT) were not observed. The new haplotype in Taiwan (H4) may be a result of recombination, with the $\mathrm{H} 1$ haplotype found elsewhere in the world. It may be that this haplotype was introduced to Taiwan and then recombined to produce $\mathrm{H} 4$. Alternatively, $\mathrm{H} 1$ and $\mathrm{H} 4$ could both have evolved in Taiwan, before the $\mathrm{H} 1$ haplotype spread elsewhere, although it is then not clear why $\mathrm{H} 4$ has failed to spread. The effect of the genotypes $\mathrm{G}$ and $\mathrm{H}$ that we found only in Taiwan on pyrethroid resistance is not known. Genotype $\mathrm{G}$ has also been recorded in Ae. aegypti in Myanmar (Kawada et al., 2014), but resistance levels of mosquitoes with this genotype were not tested.

Our analyses of resistance Profiles GTC and TGT indicate that genetic invasion is likely to have played a significant role in establishing the current distributions of their associated haplotypes. Our latent factor mixed-models detected regions surrounding the Vssc gene 4,661,744 and 12,468,872 bp long in which there were 26 and 23 SNPs closely associated with resistance profiles (Figure 4). Investigating SNPs within the Vssc region using PCA also showed these were structured by resistance profile rather than by population (Figure 5). As alleles at these SNP loci should not be conferring any selective advantage related to resistance, we can conclude that their structuring is a result of linked selection with SNPs conferring resistance. We would expect to see these SNPs structured according to population if resistance mutations had arisen de novo in populations. Instead, we see clear evidence that haplotypes $\mathrm{H} 1$ and $\mathrm{H} 2$ have genetically invaded the Indo-Pacific region. While the role of human transportation in establishing geographical distributions of Aedes mosquitoes is already well recognised (Tatem, Hay, \& Rogers, 2006), these results indicate that dispersal along transportation networks has also helped to establish current distributions of pyrethroid resistance mutations. These results stand in contrast to a similar investigation of pyrethroid resistance in 
452

453

454

455

456

457

458

459

460

461

462

463

464

465

466

467

468

469

470

471

472

473

474

475

476

477

478

479

480

Australian red-legged earth mite (Halotydeus destructor) populations, which showed that the present distribution of resistance had been attained by multiple de novo mutations (Yang et al., 2020).

We propose that a series of genetic invasions have established haplotype $\mathrm{H} 1$ in Bali, Kiribati, Malaysia, Singapore, Sri Lanka, Thailand, and Vanuatu, and have established haplotype H2 in Fiji, Kiribati, Malaysia, Singapore, Sri Lanka, Thailand, and Vietnam. The consistent structuring by resistance profile of Vssc genetic variation from these populations accords with every copy of these haplotypes sharing identity by descent. However, there is no indication from our results whether either haplotype originated in any of these populations or elsewhere within the Indo-Pacific region, which will require further sampling. For instance, we were not able to include samples from Hawaii, Tahiti, or the Philippines, three Indo-Pacific locations with interesting patterns of genetic structure relative to other Indo-Pacific populations (Gloria-Soria et al., 2016).

From our results, it seems likely that Taiwan and New Caledonia have also developed local resistance following the same genetic invasions, though these populations both had some resistant individuals that did not cluster convincingly with others having the same resistance profile (Figure 5). In Taiwan, there were two such cases: one, the clustering of Haplotype H4 along similar lines as H1 (Figure 5a), and another, the clustering of a single Profile TGT homozygote with Profile GTC individuals (Figure 5c). The first observation is best explained by the $\mathrm{H} 1$ and $\mathrm{H} 4$ haplotypes having a shared evolutionary origin, with one being the ancestral haplotype and one being derived. Determining which is ancestral is beyond the scope of this study and would, at minimum, require more widespread sampling throughout the Indo-Pacific region. The second observation is less easily explained, but potentially relates to one or more recombination events within the Vssc gene introducing variation associated with the $\mathrm{H} 1$ haplotype into the $\mathrm{H} 2$ haplotype in Taiwan. A more comprehensive investigation of resistance in Taiwanese Ae. aegypti will be necessary to resolve these issues. The imperfect clustering of New Caledonia and haplotype $\mathrm{H} 2$ (Figure $5 \mathrm{c}$ ) appears to relate more to the rareness of resistance haplotypes in New Caledonia. Only five copies of $\mathrm{H} 2$ were observed there, compared with 11 copies of the wild-type $\mathrm{H} 3$ haplotype, which likely prevented strong structuring by resistance profile. The solitary resistant homozygote (genotype B, Figure 2) from New Caledonia did cluster convincingly with other resistant homozygotes, presenting evidence for genetic invasion in this population.

This article is protected by copyright. All rights reserved 
Populations of $A e$. aegypti studied by others have shown evidence of selective sweeps affecting this gene around codons 1534 (Ishak et al., 2015) and 1016 (Wuliandari et al., 2015). Similar evidence of selection has been found in Ae. aegypti from South America around codon 1016 (Saavedra-Rodriguez et al., 2007), but segregation of South American mosquitoes from those of the Indo-Pacific region has long been recognized (Smith et al., 2016), due, in particular, to the geographic restriction of V1016I to South America. Saavedra-Rodriguez et al. (2007) showed high levels of recombination between codons 1011 and 1016 in Ae. aegypti from South America, but mutations at 1011 have are not been recorded in Ae. aegypti from the Indo-Pacific or southeast Asia (Kawada et al., 2009; Kawada et al., 2014; Smith et al., 2016). Evidence for local selection of pyrethroid resistance has been obtained in Ae. aegypti from Mexico (Saavedra-Rodriguez et al., 2015). V1016G appears to have arisen before S989P (C.-X. Li et al., 2015), as S989P is never (Kawada et al., 2014) or rarely (Wuliandari et al., 2015) found alone. Our data indicate that some sites have likely reached a stable point of resistance (e.g. Bali, Vanuatu) given that genotypes are fixed. However, others are in flux and we expect that the resistance we have recorded may change in the future. A recent study of Ae. aegypti in Taiwan (Biduda et al., 2019) has shown an increase over time in frequency of the $1534 \mathrm{C}$ mutation, indicating that this population is still undergoing change.

Smith et al. (2016) summarised the findings of multiple studies on the combinations of mutations that lead to pyrethroid resistance as follows: the V1016G mutation found alone confers resistance to Type I (those without an $\alpha$-cyano group) and Type II pyrethroids (those with an $\alpha$-cyano-3phenoxybenzyl group) whereas F1534C alone confers resistance only to pyrethroids of Type I and to DDT (Du, Nomura, Zhorov, \& Dong, 2016a). The degree of resistance induced by V1016G alone is four times that of F1534C alone when expressed in Xenopus oocytes (Hirata et al., 2014). S989P alone in Xenopus oocyte trials has not been shown to confer resistance (Hirata et al., 2014). The geographic haplotype distribution we have observed in Ae. aegypti from the Indo-Pacific suggests that mosquito control in Bali and Vanuatu will be very difficult with both Type I and Type II pyrethroids. Some pyrethroid efficacy is likely to have been lost to various degrees in Taiwan, Kiribati, Malaysia, Singapore, Sri Lanka and Thailand. Mosquito control in Fiji, Vietnam and New Caledonia with Type I pyrethroids may be compromised, but Type II pyrethroids are likely to remain effective. 
512 The potential impacts of resistance conferred by Vssc mutations, however, may be modified by other

513 factors. For example, Du et al. (2016b) noted context dependent effects of combinations of Vssc

514 mutations likely related to genetic background of the mosquito. Smith et al. (2019) found that a

515 combination of $k d r$ and CYP-mediated metabolic detoxification of insecticides confers a greater than

516 additive level of resistance to Ae. aegypti, so there may be a selective advantage to mosquitoes

517 having both mechanisms. In that case, the spread of $k d r$ mutations that we observed may have been

518 accompanied by the spread of other resistance mechanisms.

520 Our approach of looking at the Vssc mutations in the context of genetic population structure helps

521 indicate the extent of movement of resistance alleles in Ae. aegypti in the Indo-Pacific and provides

522 little evidence for independent evolution of pyrethroid resistance in different populations

523 throughout the region. The results of this study likely reflect a series of genetic invasions that have

524 proceeded from the initial biological invasions of the Indo-Pacific by Ae. aegypti (J. E. Brown et al.,

525 2014). These invasions have introduced sets of allele combinations conferring resistance to

526 insecticides used in the region. Our results point to the importance of biosecurity controls to prevent

527 resistance alleles moving to new areas with mosquito incursions. Insecticide resistance pressures

528 within a country need to be reduced in order to prevent resistance alleles becoming fixed in

529 mosquito populations.

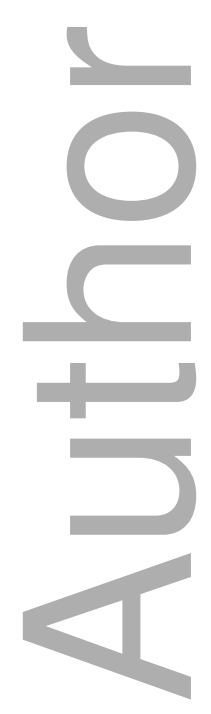

This article is protected by copyright. All rights reserved 
531 We thank our mosquito collectors - Ashley Callahan, Jason Axford, Tim Hurst, Elizabeth Valerie, Craig

532 Williams. The study was funded by the Department of Agriculture and Water Resources (DAWR),

533 Australian Government; National Health and Medical Research Council with a Programme

534 Grant/Award Numbers: 1037003, 1132412; a Fellowship to Ary A. Hoffmann, NHMRC Fellowship

535 Grant no. 1118640 and the Wellcome Trust, UK. This research was facilitated by use of the Nectar

536 Research Cloud, a collaborative Australian research platform supported by the Australian Research

537 Data Commons (ARDC) and National Collaborative Research Infrastructure Strategy (NCRIS).

538

539

Data Accessibility Statement

540 Resistance genotype data are available within the manuscript. The aligned .bam sequence files are

541 available through the Sequence Read Archive at NCBI Genbank, BioProject ID PRJNA608612.

542

\section{Author Contributions}

544 NMEH, TLS, AAH designed the study. NMEH, TLS, JC performed research and analysed data. AvR

545 contributed assay design. NMEH, TLS, AAH, JC and ARW wrote the paper.

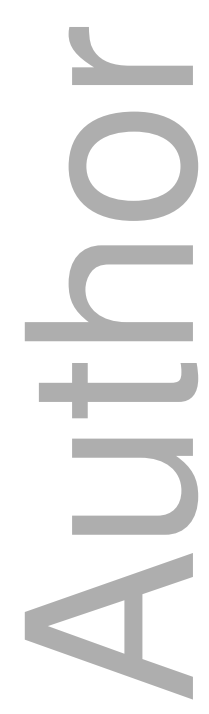

This article is protected by copyright. All rights reserved 
Al Nazawi, A. M., Aqili, J., Alzahrani, M., McCall, P. J., \& Weetman, D. (2017). Combined target site $(k d r)$ mutations play a primary role in highly pyrethroid resistant phenotypes of Aedes

552

553

554

555

556

557

558

559

560

561

562

563

564

565

566

567

568

569

570

571

572

573

574

575

576

577 aegypti from Saudi Arabia. Parasites \& Vectors, 10(1), 161. doi:10.1186/s13071-017-2096-6

Bennett, K. E., Flick, D., Fleming, K. H., Jochim, R., Beaty, B. J., \& Black, W. C. (2005). Quantitative Trait Loci that control Dengue-2 virus dissemination in the mosquito Aedes aegypti. Genetics, 170(1), 185. doi:10.1534/genetics.104.035634

Biduda, S., Lin, C.-H., Saleh, F., Konradsen, F., Hansson, H., Schiøler, K. L., \& Alifrangis, M. (2019). Temporal pattern of mutations in the knockdown resistance $(k d r)$ gene of Aedes aegypti mosquitoes sampled from Southern Taiwan. The American Journal of Tropical Medicine and Hygiene. doi:https://doi.org/10.4269/ajtmh.19-0289

Brito, L. P., Linss, J. G. B., Lima-Camara, T. N., Belinato, T. A., Peixoto, A. A., Lima, J. B. P., . . Martins, A. J. (2013). Assessing the effects of Aedes aegypti kdr mutations on pyrethroid resistance and its fitness cost. PLoS One, 8(4), e60878. doi:10.1371/journal.pone.0060878

Brown, J.E., Evans, B. R., Zheng, W., Obas, V., Barrera-Martinez, L., Egizi, A., . . Powell, J. R. (2014). Human impacts have shaped historical and recent evolution in Aedes aegypti, the dengue and yellow fever mosquito. Evolution, 68(2), 514-525. doi:10.1111/evo.12281

Brown, S. E., Severson, D. W., Smith, L. A., \& Knudson, D. L. (2001). Integration of the Aedes aegypti mosquito genetic linkage and physical maps. Genetics, 157(3), 1299.

Catchen, J., Hohenlohe, P. A., Bassham, S., Amores, A., \& Cresko, W. A. (2013). Stacks: an analysis tool set for population genomics. Molecular Ecology, 22(11), 3124-3140. doi:10.1111/mec.12354

Chang, C., Huang, X.-Y., Chang, P.-C., Wu, H.-H., \& Dai, S.-M. (2012). Inheritance and stability of sodium channel mutations associated with permethrin knockdown resistance in Aedes aegypti. Pesticide Biochemistry \& Physiology, 104(2), 136-142. doi:10.1016/j.pestbp.2012.06.003

Chang, C., Shen, W.-K., Wang, T.-T., Lin, Y.-H., Hsu, E.-L., \& Dai, S.-M. (2009). A novel amino acid substitution in a voltage-gated sodium channel is associated with knockdown resistance to permethrin in Aedes aegypti. Insect Biochemistry \& Molecular Biology, 39(4), 272-278. doi:10.1016/j.ibmb.2009.01.001 
Chen, M., Du, Y., Wu, S., Nomura, Y., Zhu, G., Zhorov, B. S., \& Dong, K. (2019). Molecular evidence of sequential evolution of DDT- and pyrethroid-resistant sodium channel in Aedes aegypti. PLoS Negl Trop Dis, 13(6), e0007432. doi:10.1371/journal.pntd.0007432

Chevillon, C., Raymond, M., Guillemaud, T., Lenormand, T., \& Pasteur, N. (1999). Population genetics of insecticide resistance in the mosquito Culex pipiens. Biological Journal of the Linnean Society, 68(1-2), 147-157. doi:10.1111/j.1095-8312.1999.tb01163.x

Danecek, P., Auton, A., Abecasis, G., Albers, C. A., Banks, E., DePristo, M. A., . . Genomes Project Analysis, G. (2011). The variant call format and VCFtools. Bioinformatics, 27(15), 2156-2158. doi:10.1093/bioinformatics/btr330

Du, Y., Nomura, Y., Satar, G., Hu, Z., Nauen, R., He, S. Y., . . Dong, K. (2013). Molecular evidence for dual pyrethroid-receptor sites on a mosquito sodium channel. Proceedings of the National Academy of Sciences, 110(29), 11785-11790.

Du, Y., Nomura, Y., Zhorov, B. S., \& Dong, K. (2016a). Evidence for dual binding sites for 1,1,1trichloro-2,2-bis(p-chlorophenyl)ethane (DDT) in insect sodium channels. Journal of Biological Chemistry, 291(9), 4638-4648.

Du, Y., Nomura, Y., Zhorov, B. S., \& Dong, K. (2016b). Sodium channel mutations and pyrethroid resistance in Aedes aegypti. Insects, 7(4), 1-11. doi:10.3390/insects7040060

Endersby-Harshman, N. M., Wuliandari, J. R., Harshman, L. G., Frohn, V., Johnson, B. J., Ritchie, S. A., \& Hoffmann, A. A. (2017). Pyrethroid susceptibility has been maintained in the dengue vector, Aedes aegypti (Diptera: Culicidae), in Queensland, Australia. J Med Entomol, 54(6), 1649-1658. doi:10.1093/jme/tjx145

Frichot, E., \& François, O. (2015). LEA: An R package for landscape and ecological association studies. Methods in Ecology and Evolution, 6(8), 925-929. doi:10.1111/2041-210X.12382

Frichot, E., Schoville, S. D., Bouchard, G., \& François, O. (2013). Testing for associations between loci and environmental gradients using latent factor mixed models. Molecular Biology and Evolution, 30(7), 1687-1699. doi:10.1093/molbev/mst063

Gloria-Soria, A., Ayala, D., Bheecarry, A., Calderon-Arguedas, O., Chadee, D. D., Chiappero, M., . . . Powell, J. R. (2016). Global genetic diversity of Aedes aegypti. Molecular Ecology, 25(21), 5377-5395. doi:10.1111/mec.13866

Gloria-Soria, A., Lima, A., Lovin, D. D., Cunningham, J. M., Severson, D. W., \& Powell, J. R. (2018). Origin of a high-latitude population of Aedes aegypti in Washington, DC. Am J Trop Med Hyg, 98(2), 445-452. doi:10.4269/ajtmh.17-0676

This article is protected by copyright. All rights reserved 
610

611

612

613

614

615

616

617

618

619

620

621

622

623

624

625

626

627

628

629

630

631

632

633

634

635

636

637

638

639

640

641

Haddi, K., Tomé, H. V. V., Du, Y., Valbon, W. R., Nomura, Y., Martins, G. F., . . Oliveira, E. E. (2017). Detection of a new pyrethroid resistance mutation (V410L) in the sodium channel of Aedes aegypti: a potential challenge for mosquito control. Scientific Reports, 7, 46549. doi:10.1038/srep46549

Hirata, K., Komagata, O., Itokawa, K., Yamamoto, A., Tomita, T., \& Kasai, S. (2014). A single crossingover event in voltage-sensitive $\mathrm{Na}+$ channel genes may cause critical failure of dengue mosquito control by insecticides. PLoS NegPLoS Neglected Tropical Diseases, 8(8), e3085. doi:10.1371/journal.pntd.0003085

Ishak, I. H., Jaal, Z., Ranson, H., \& Wondji, C. S. (2015). Contrasting patterns of insecticide resistance and knockdown resistance $(k d r)$ in the dengue vectors Aedes aegypti and Aedes albopictus from Malaysia. Parasites \& Vectors, 8(1), 1-13. doi:10.1186/s13071-015-0797-2

Jasper, M., Schmidt, T. L., Ahmad, N. W., Sinkins, S. P., \& Hoffmann, A. A. (2019). A genomic approach to inferring kinship reveals limited intergenerational dispersal in the yellow fever mosquito. Molecular Ecology Resources, O(0). doi:10.1111/1755-0998.13043

Kasai, S., Komagata, O., Itokawa, K., Shono, T., Ng, L. C., Kobayashi, M., \& Tomita, T. (2014). Mechanisms of pyrethroid resistance in the dengue mosquito vector, Aedes aegypti: target site insensitivity, penetration, and metabolism. PLoS Neglected Tropical Diseases, 8(6), e2948. doi:10.1371/journal.pntd.0002948

Kawada, H., Higa, Y., Futami, K., Muranami, Y., Kawashima, E., Osei, J. H., . . Minakawa, N. (2016). Discovery of point mutations in the Voltage-Gated Sodium Channel from African Aedes aegypti populations: Potential phylogenetic reasons for gene introgression. PLoS Neglected Tropical Diseases, 10(6), e0004780. doi:10.1371/journal.pntd.0004780

Kawada, H., Higa, Y., Komagata, O., Kasai, S., Tomita, T., Nguyen Thi, Y., . . Takagi, M. (2009). Widespread distribution of a newly found point mutation in Voltage-Gated Sodium Channel in pyrethroid-resistant Aedes aegypti populations in Vietnam. PLoS Neglected Tropical Diseases, 3(10), 1-7. doi:10.1371/journal.pntd.0000527

Kawada, H., Oo, S. Z. M., Thaung, S., Kawashima, E., Maung, Y. N. M., Thu, H. M., . . Minakawa, N. (2014). Co-occurrence of point mutations in the Voltage-Gated Sodium Channel of pyrethroid-resistant Aedes aegypti populations in Myanmar. PLoS Neglected Tropical Diseases, 8(7), 1-8. doi:10.1371/journal.pntd.0003032

Langmead, B., \& Salzberg, S. L. (2012). Fast gapped-read alignment with Bowtie 2. Nature methods, 9(4), 357-359. doi:10.1038/nmeth.1923

This article is protected by copyright. All rights reserved 
Leong, C. S., Vythilingam, I., Liew, J. W. K., Wong, M. L., Wan-Yusoff, W. S., \& Lau, Y. L. (2019). Enzymatic and molecular characterization of insecticide resistance mechanisms in field populations of Aedes aegypti from Selangor, Malaysia. Parasites and Vectors, 12(1). doi:10.1186/s13071-019-3472-1

Li, C.-X., Kaufman, P. E., Xue, R.-D., Zhao, M.-H., Wang, G., Yan, T., . . Zhao, T.-Y. (2015). Relationship between insecticide resistance and $k d r$ mutations in the dengue vector Aedes aegypti in Southern China. Parasites \& Vectors(325). doi:10.1186/s13071-015-0933-z

$\mathrm{Li}, \mathrm{H}$. (2014). Toward better understanding of artifacts in variant calling from high-coverage samples. Bioinformatics (Oxford, England), 30(20), 2843-2851. doi:10.1093/bioinformatics/btu356

Lin, Y.-H., Tsen, W.-L., Tien, N.-Y., \& Luo, Y.-P. (2013). Biochemical and molecular analyses to determine pyrethroid resistance in Aedes aegypti. Pesticide Biochemistry and Physiology, 107(2), 266-276. doi:https://doi.org/10.1016/j.pestbp.2013.08.004

Linck, E., \& Battey, C. J. (2019). Minor allele frequency thresholds strongly affect population structure inference with genomic data sets. Molecular Ecology Resources, 19(3), 639-647. doi:10.1111/1755-0998.12995

Loiselle, B. A., Sork, V. L., Nason, J., \& Graham, C. (1995). Spatial genetic structure of a tropical understory shrub, Psychotria officinalis (Rubiaceae). American Journal of Botany, 82(11), 1420-1425. doi:10.1002/j.1537-2197.1995.tb12679.x

Matthews, B. J., Dudchenko, O., Kingan, S. B., Koren, S., Antoshechkin, I., Crawford, J. E., . . Vosshall, L. B. (2018). Improved reference genome of Aedes aegypti informs arbovirus vector control. Nature, 563(7732), 501-507. doi:10.1038/s41586-018-0692-z

Moyes, C. L., Vontas, J., Martins, A. J., Ng, L. C., Koou, S. Y., Dusfour, I., . . Weetman, D. (2017). Contemporary status of insecticide resistance in the major Aedes vectors of arboviruses infecting humans. PLoS Neglected Tropical Diseases, 11(7), e0005625. doi:10.1371/journal.pntd.0005625

Nagoshi, R. N., Fleischer, S., Meagher, R. L., Hay-Roe, M., Khan, A., Murúa, M. G., . . Westbrook, J. (2017). Fall armyworm migration across the Lesser Antilles and the potential for genetic exchanges between North and South American populations. PLoS One, 12(2), e0171743. doi:10.1371/journal.pone.0171743

Plernsub, S., Saingamsook, J., Yanola, J., Lumjuan, N., Tippawangkosol, P., Sukontason, K., . . . Somboon, P. (2016). Additive effect of knockdown resistance mutations, S989P, V1016G and F1534C, in a heterozygous genotype conferring pyrethroid resistance in Aedes aegypti in Thailand. Parasites \& Vectors, 9(1), 417. doi:10.1186/s13071-016-1713-0 
Plernsub, S., Saingamsook, J., Yanola, J., Lumjuan, N., Tippawangkosol, P., Walton, C., \& Somboon, P. (2016). Temporal frequency of knockdown resistance mutations, F1534C and V1016G, in Aedes aegypti in Chiang Mai city, Thailand and the impact of the mutations on the efficiency of thermal fogging spray with pyrethroids. Acta Tropica, 162, 125-132. doi:http://dx.doi.org/10.1016/j.actatropica.2016.06.019

Rašić, G., Filipović, l., Weeks, A. R., \& Hoffmann, A. A. (2014). Genome-wide SNPs lead to strong signals of geographic structure and relatedness patterns in the major arbovirus vector, Aedes aegypti. BMC Genomics, 15(1), 275. doi:10.1186/1471-2164-15-275

Saavedra-Rodriguez, K., Beaty, M., Lozano-Fuentes, S., Denham, S., Garcia-Rejon, J., Reyes-Solis, G., . . . Black, W. C. (2015). Local evolution of pyrethroid resistance offsets gene flow among Aedes aegypti collections in Yucatan State, Mexico. The American Journal of Tropical Medicine and Hygiene, 92(1), 201-209. doi:10.4269/ajtmh.14-0277

Saavedra-Rodriguez, K., Urdaneta-Marquez, L., Rajatileka, S., Moulton, M., Flores, A. E., FernandezSalas, l.,.... Black IV, W. C. (2007). A mutation in the voltage-gated sodium channel gene associated with pyrethroid resistance in Latin American Aedes aegypti. Insect Molecular Biology, 16(6), 785-798.

Sayono, S., Hidayati, A. P. N., Fahri, S., Sumanto, D., Dharmana, E., Hadisaputro, S., . . Syafruddin, D. (2016). Distribution of Voltage-Gated Sodium Channel (Nav) alleles among the Aedes aegypti populations in Central Java Province and its association with resistance to pyrethroid insecticides. PLoS One, 11(3), 1-12. doi:10.1371/journal.pone.0150577

Schmidt, T. L., Filipovic, I., Hoffmann, A. A., \& Rasic, G. (2018). Fine-scale landscape genomics helps explain the slow spatial spread of Wolbachia through the Aedes aegypti population in Cairns, Australia. Heredity (Edinb), 120(5), 386-395. doi:10.1038/s41437-017-0039-9

Schmidt, T. L., van Rooyen, A. R., Chung, J., Endersby-Harshman, N. M., Griffin, P. C., Sly, A., . . . Weeks, A. R. (2019). Tracking genetic invasions: Genome-wide single nucleotide polymorphisms reveal the source of pyrethroid-resistant Aedes aegypti (yellow fever mosquito) incursions at international ports. Evolutionary Applications, 12(6), 1136-1146. doi:10.1111/eva.12787

Sherpa, S., Rioux, D., Goindin, D., Fouque, F., François, O., \& Després, L. (2017). At the origin of a worldwide invasion: Unraveling the genetic makeup of the Caribbean bridgehead populations of the dengue vector Aedes aegypti. Genome Biology and Evolution, 10(1), 5671. doi:10.1093/gbe/evx267 
Shi, P., Cao, L.-J., Gong, Y.-J., Ma, L., Song, W., Chen, J.-C., . . Wei, S.-J. (2019). Independently evolved and gene flow-accelerated pesticide resistance in two-spotted spider mites. Ecology and Evolution, 9. doi:10.1002/ece3.4916

Smith, L. B., Kasai, S., \& Scott, J. G. (2016). Pyrethroid resistance in Aedes aegypti and Aedes albopictus: Important mosquito vectors of human diseases. Pesticide Biochemistry \& Physiology, 133, 1-12. doi:10.1016/j.pestbp.2016.03.005

Smith, L. B., Sears, C., Sun, H., Mertz, R. W., Kasai, S., \& Scott, J. G. (2019). CYP-mediated resistance and cross-resistance to pyrethroids and organophosphates in Aedes aegypti in the presence and absence of kdr. Pesticide Biochemistry and Physiology, 160, 119-126. doi:10.1016/j.pestbp.2019.07.011

Stenhouse, S. A., Plernsub, S., Yanola, J., Lumjuan, N., Dantrakool, A., Choochote, W., \& Somboon, P. (2013). Detection of the V1016G mutation in the voltage-gated sodium channel gene of Aedes aegypti (Diptera: Culicidae) by allele-specific PCR assay, and its distribution and effect on deltamethrin resistance in Thailand. Parasites \& Vectors, 6(1), 253-253. doi:10.1186/1756-3305-6-253

Tatem, A. J., Hay, S. I., \& Rogers, D. J. (2006). Global traffic and disease vector dispersal. Proceedings of the National Academy of Sciences, 103(16), 6242-6247. doi:10.1073/pnas.0508391103

Williamson, M. S., Denholm, I., Bell, C. A., \& Devonshire, A. L. (1993). Knockdown resistance (kdr) to DDT and pyrethroid insecticides maps to a sodium channel gene locus in the housefly (Musca domestica). Molecular and General Genetics, 240(1), 17-22. doi:10.1007/BF00276878

Willing, E. M., Dreyer, C., \& van Oosterhout, C. (2012). Estimates of genetic differentiation measured by $F(S T)$ do not necessarily require large sample sizes when using many SNP markers. PLoS One, 7(8), e42649. doi:10.1371/journal.pone.0042649

Wuliandari, J., Lee, S., White, V., Tantowijoyo, W., Hoffmann, A., \& Endersby-Harshman, N. (2015). Association between three mutations, F1565C, V1023G and S996P, in the voltage-sensitive sodium chānnel gene and knockdown resistance in Aedes aegypti from Yogyakarta, Indonesia. Insects, 6(3), 658.

Yang, Q., Umina, P. A., Rašić, G., Bell, N., Fang, J., Lord, A., \& Hoffmann, A. A. (2020). Origin of resistance to pyrethroids in the redlegged earth mite (Halotydeus destructor) in Australia: repeated local evolution and migration. Pest Management Science, 76(2), 509-519. doi:10.1002/ps.5538

Yanola, J., Somboon, P., Walton, C., Nachaiwieng, W., Somwang, P., \& Prapanthadara, L.-a. (2011). High-throughput assays for detection of the F1534C mutation in the voltage-gated sodium 


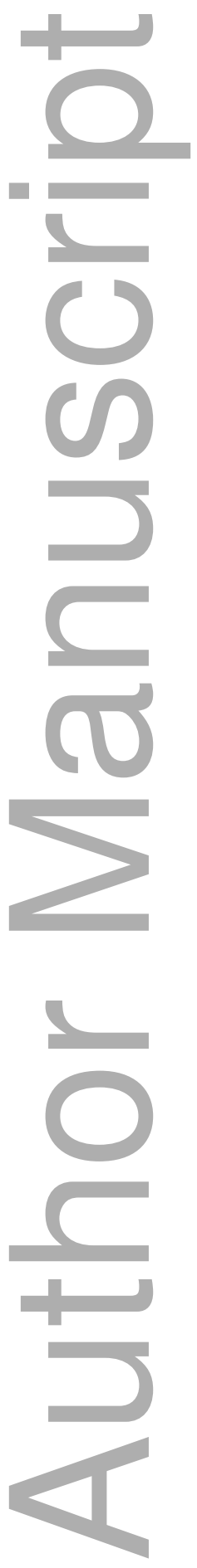


Table 1. Custom TaqMan ${ }^{\circledR}$ SNP Genotyping Assays (Life Technologies, California, USA) for each of three target site mutations in the Vssc gene of Aedes aegyptifrom the Indo-Pacific

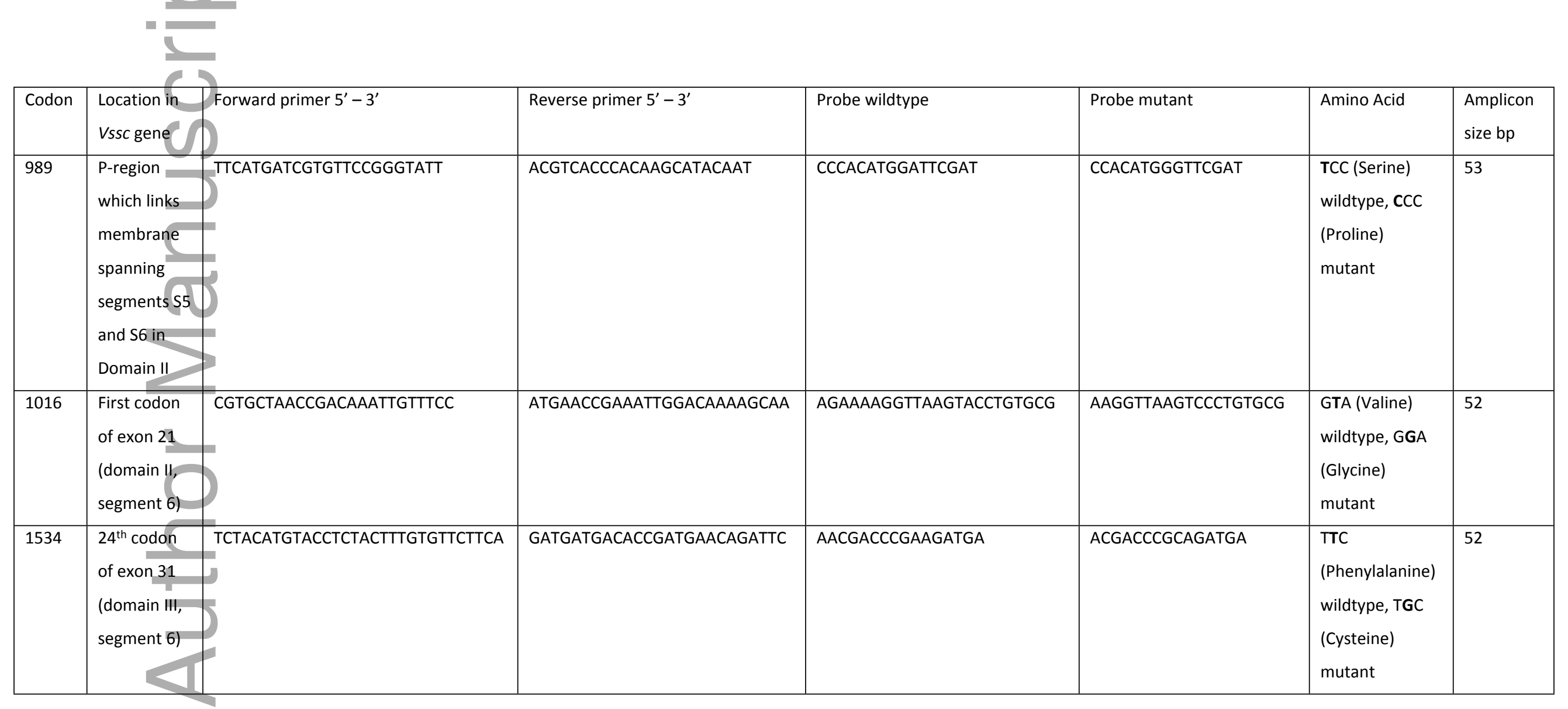

This article is protected by copyright. All rights reserved 
Table 2. Frequency of Vssc kdr genotypes identified in Ae. aegypti from specific countries in the Indo-Pacific region

\begin{tabular}{|c|c|c|c|c|c|c|c|c|c|c|}
\hline $\begin{array}{l}\text { Genotype code: } \\
\text { 1016/1534/989: } \\
\text { Country }\end{array}$ & $\mathbf{n}$ & Profile: & $\begin{array}{c}\text { A } \\
\text { GGTTCC } \\
\text { GTC }\end{array}$ & $\begin{array}{r}\text { B } \\
\text { TTGGTT } \\
\text { TGT }\end{array}$ & $\begin{array}{c}\text { C } \\
\text { TGTGTC } \\
\text { GTC, TGT }\end{array}$ & $\begin{array}{c}\text { D } \\
\text { TGTTTC } \\
\text { GTC }\end{array}$ & $\begin{array}{c}\text { E } \\
\text { TTTGTT } \\
\text { TGT }\end{array}$ & \begin{tabular}{r}
\multicolumn{1}{c}{$\mathbf{F}$} \\
TTTTTT \\
TTT
\end{tabular} & $\begin{array}{r}\text { G } \\
\text { GGTTTC } \\
\text { GTC }\end{array}$ & $\begin{array}{r}\text { H } \\
\text { TGTGTT } \\
\text { TGT }\end{array}$ \\
\hline Taiwan & 20 & & 0.05 & 0.60 & 0.10 & & & & 0.15 & 0.10 \\
\hline Sri Lanka & 24 & & & 0.17 & & 0.04 & 0.63 & 0.17 & & \\
\hline Indonesia (Bali) & 67 & & 1.00 & & & & & & & \\
\hline Singap & 29 & & 0.21 & 0.24 & 0.55 & & & & & \\
\hline Malays & 30 & & & 0.40 & 0.60 & & & & & \\
\hline Thaila & 40 & & 0.25 & 0.50 & 0.25 & & & & & \\
\hline Vietnam & 97 & & & 0.11 & & & 0.47 & 0.41 & & \\
\hline Vanuatu & 20 & & 1.00 & & & & & & & \\
\hline New Caledonia & 24 & & & 0.04 & & & 0.33 & 0.63 & & \\
\hline Fiji & 24 & & & 0.71 & & & 0.21 & 0.08 & & \\
\hline Kiribati & 20 & & 0.10 & 0.45 & 0.25 & 0.05 & 0.15 & & & \\
\hline TOTAL & 395 & & 0.27 & 0.23 & 0.13 & 0.01 & 0.19 & 0.15 & 0.01 & 0.01 \\
\hline
\end{tabular}

This article is protected by copyright. All rights reserved 


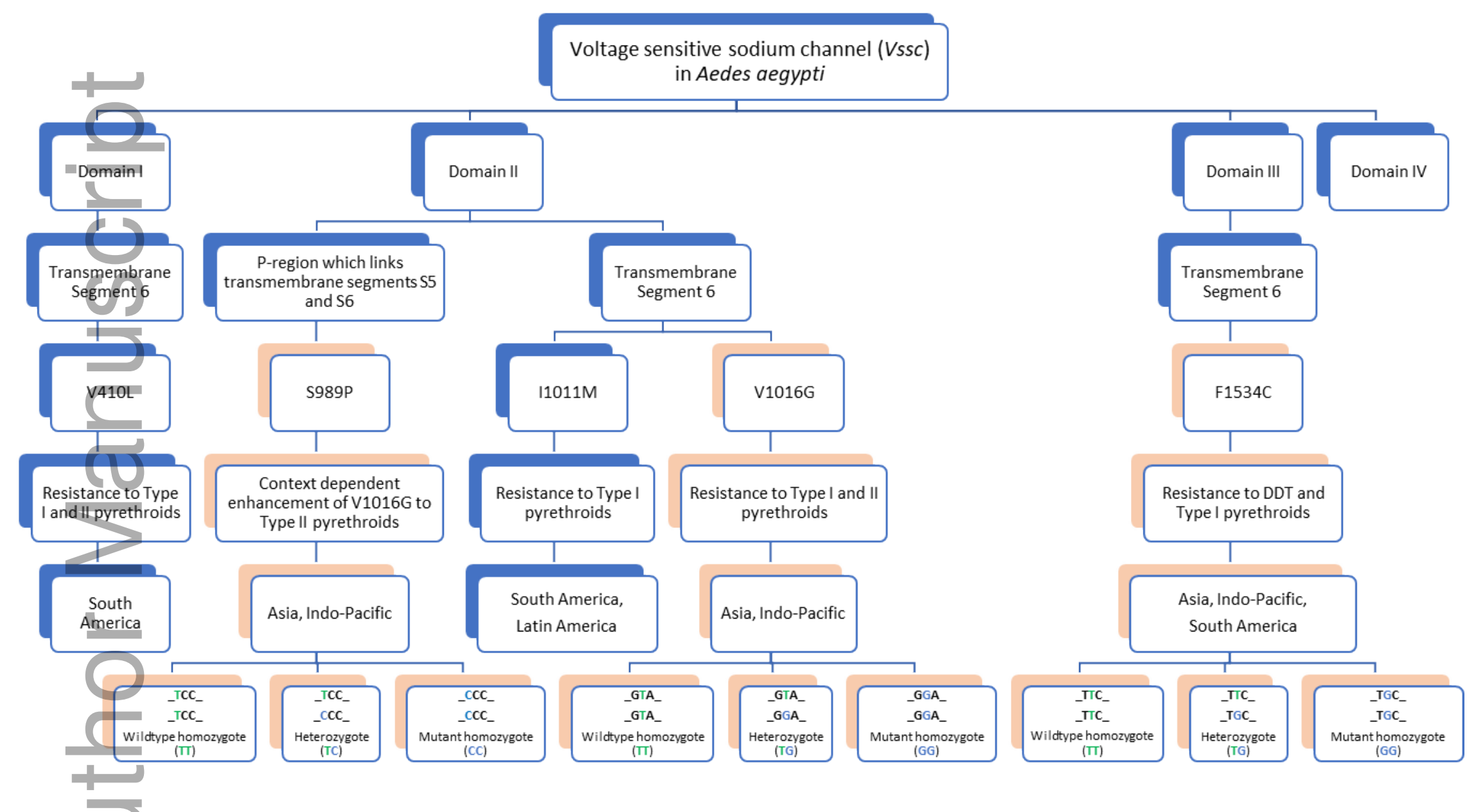

Figure 1. Key to Vssc mutations in Aedes aegypti that have been functionally characterised and shown to affect the Vssc (except for S989P). Codons are numbered according to the homologous sodium channel gene in the house fly, Musca domestica. Pink boxes refer to mutations screened in mosquitoes from the Indo-Pacific in this study. Information has been compiled from (Du et al., 2013; Du et al., 2016b; Haddi et al., 2017; SaavedraRodriguez et al., 2007; Wuliandari et al., 2015).

This article is protected by copyright. All rights reserved 
a.

b.
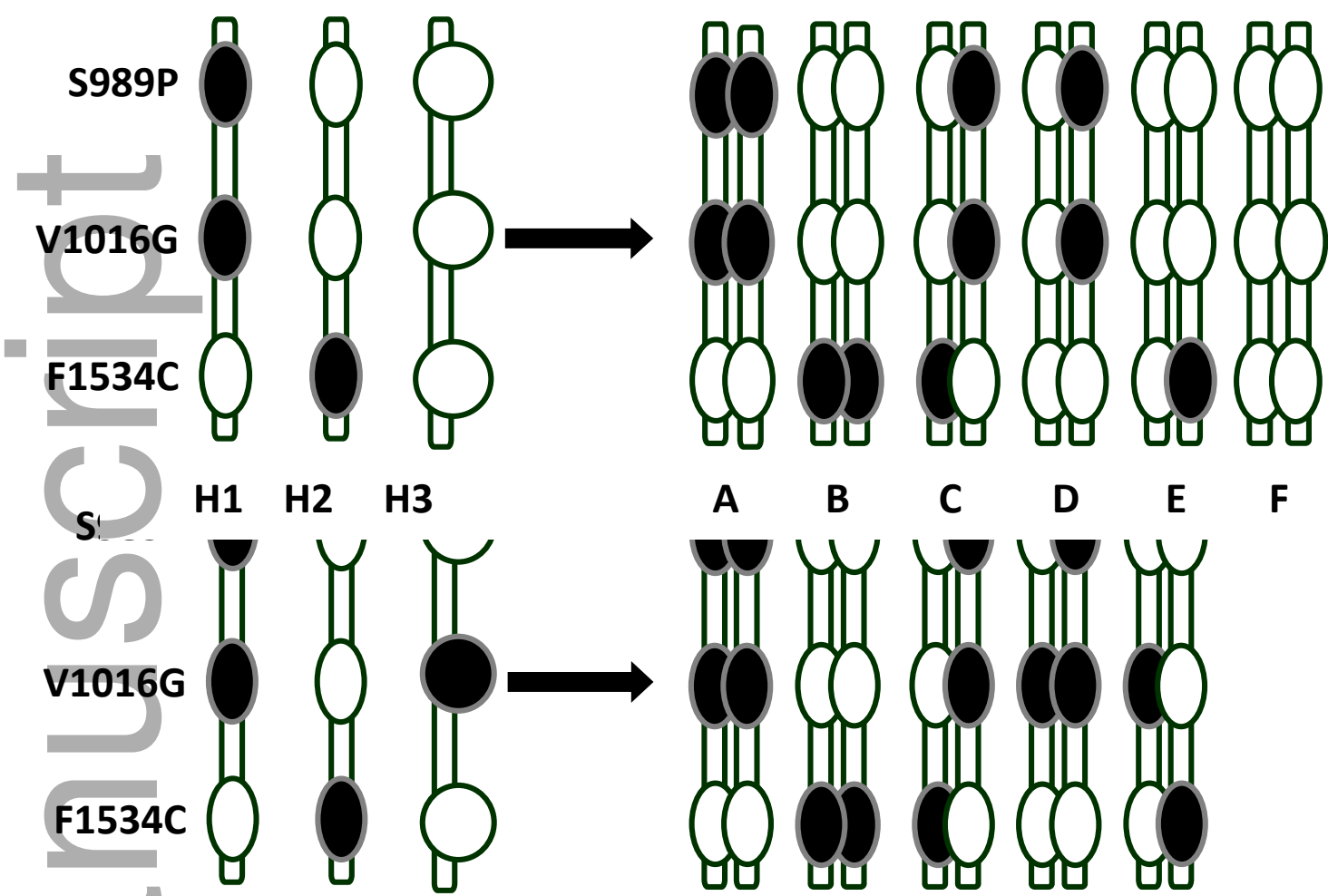

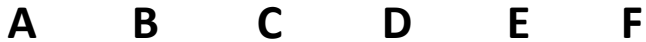

H1 H2 H4

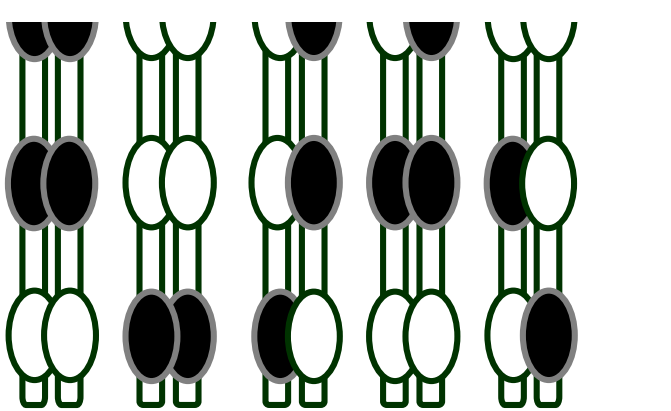

A $\quad$ B $\quad$ C $\quad$ G $\quad$ H

Figure 2 a). Putative

haplotypes and phase of

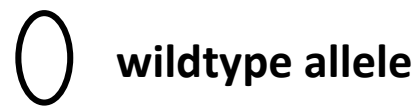

mutant allele

common mutant Vssc kdr genotypes of Aedes aegypti found in the Indo-Pacific region (excluding Taiwan sample), b) Putative haplotypes required to construct genotypes found in Taiwan sample. (Note that $\mathrm{H} 1=$ Profile GTC and H2 = Profile TGT).

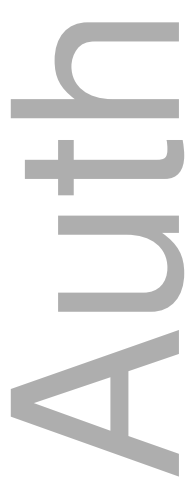



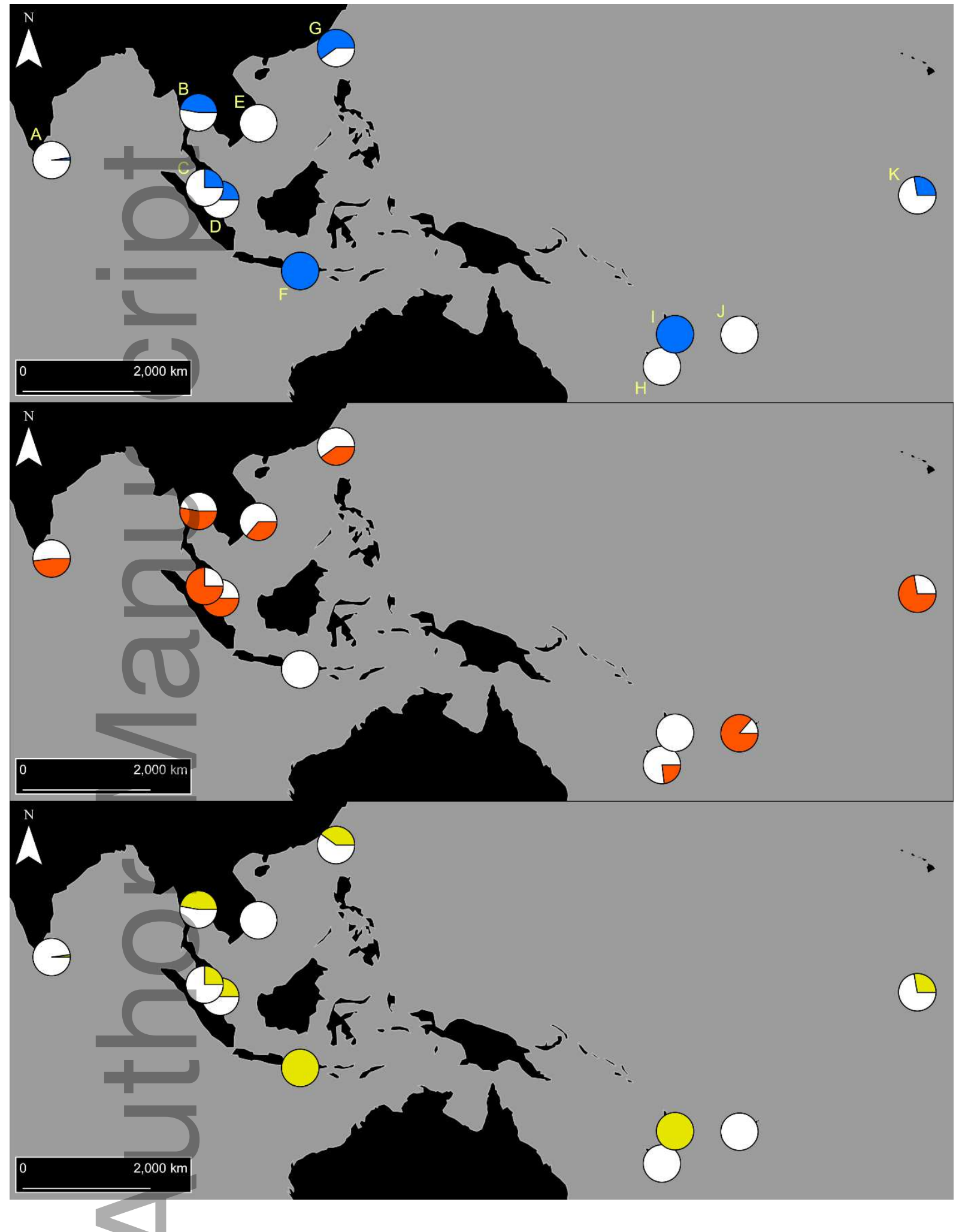

Figure 3. Distribution of the Vssc mutations in Indo-Pacific Aedes aegypti considered in this study. Coloured sectors indicate the frequency of each type of resistance mutation within each country, following: Blue $=1016 \mathrm{G}$, Orange $=1534 \mathrm{C}$, Yellow $=$ 989P. Populations are: $(\mathrm{A})$ Sri Lanka, $(\mathrm{B})$ Thailand, 
(C) Malaysia, (D) Singapore, (E) Vietnam, (F) Bali, (G) Taiwan, (H) New Caledonia, (I) Vanuatu, (J) Fiji, and (K) Kiribati.

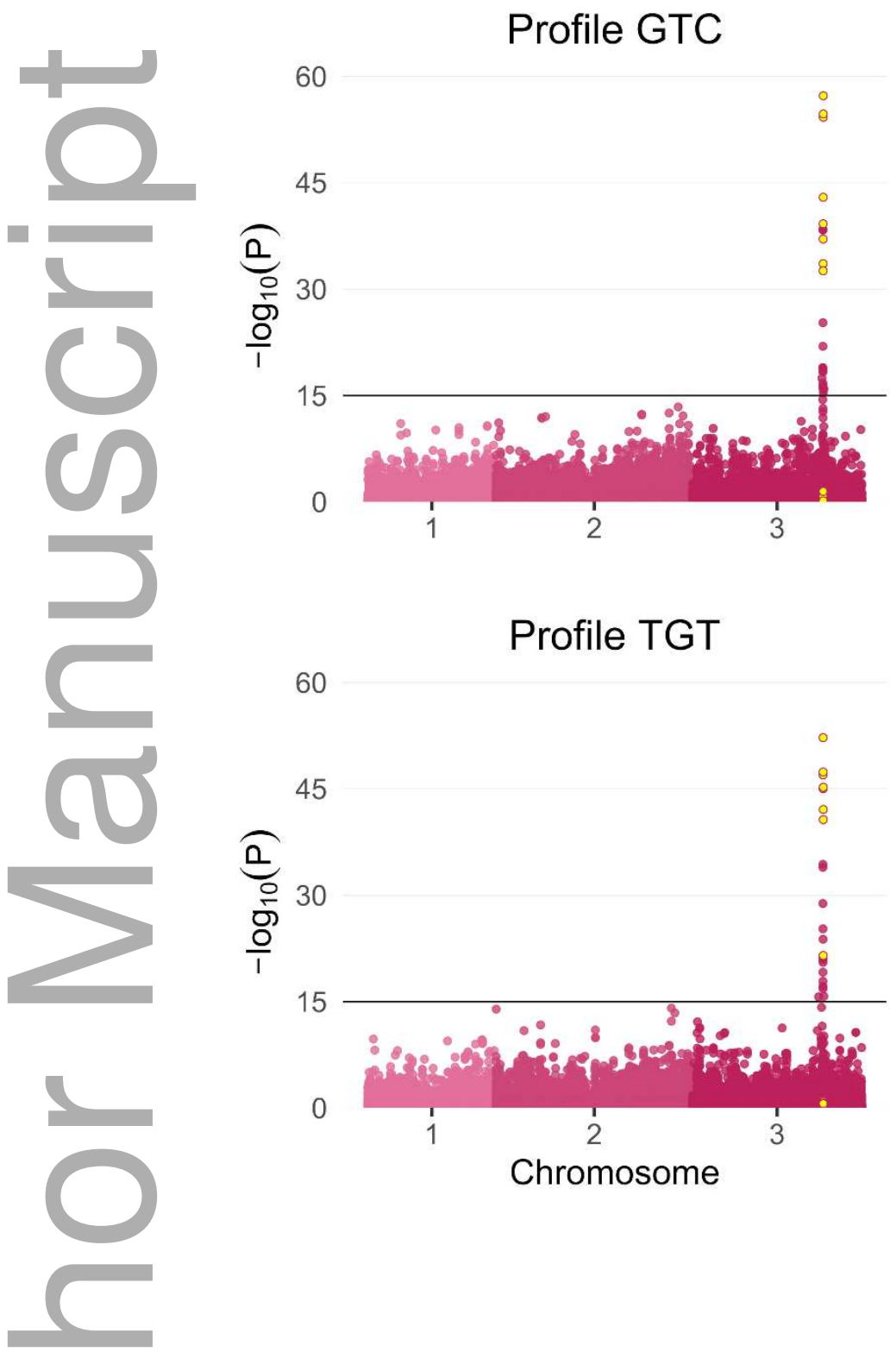

Figure 4. Latent factor mixed-models for Profiles GTC (top) and TGT (bottom).

Models use $K=4$ to condition for population structure among the $80 \mathrm{Ae}$. aegypti. Circles indicate locations and $-\log _{10}(P)$ of SNPs. Yellow-filled circles indicate SNPs located within the Vssc gene (chromosome 3; positions 315,926,360 - 316,405,638). 

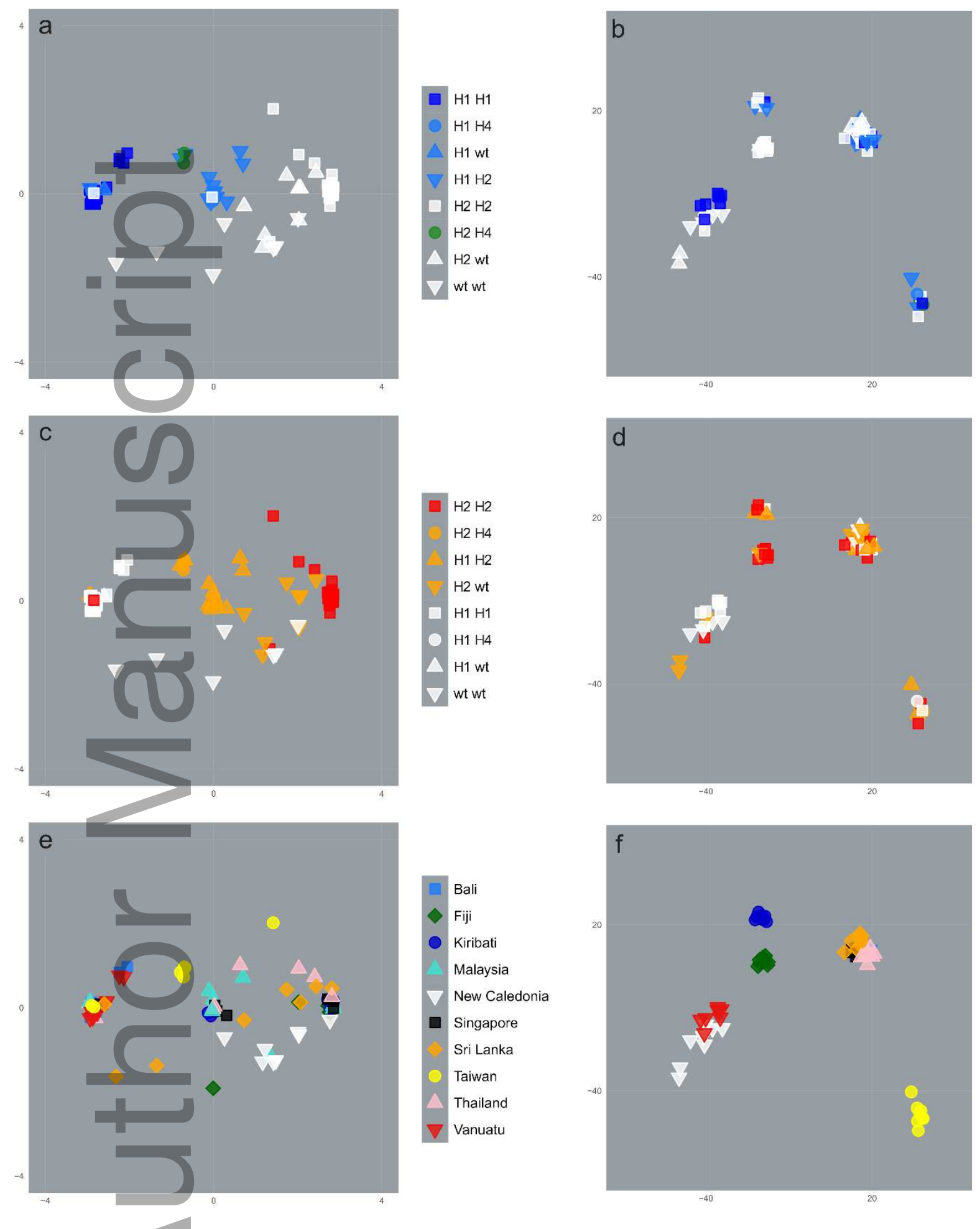

Figure 5. PCAs of 80 Ae. aegypti from 10 countries.

PCAs show variation at 18 SNPs within the Vssc gene (a, c, e) and at 50,551 SNPs outside the VssC gene $(b, d, f)$. PCAs use symbols indicating: individuals of Profile GTC and not of GTC $(a, b)$; individuals of Profile TGT and not of TGT (c, d); and individuals by population (e, f). The green colour used in (a) 
and (b) reflects the uncertainty surrounding the evolutionary history of haplotype 4. For a, c, and e: $P C 1(x$-axis) variation $=77.1 \%, P C 2(y$-axis $)=5.9 \%$. For $b, d$, and $f: P C 1(x$-axis) variation $=6.7 \%, P C 2$ $(y$-axis $)=4.3 \%$.

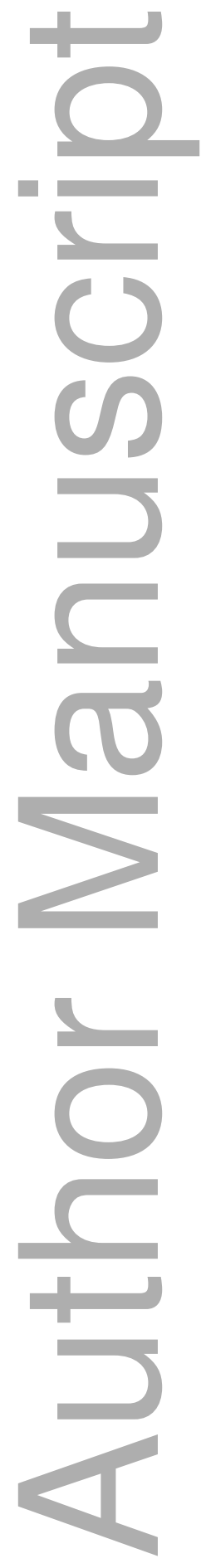


Table 1. TaqMan ${ }^{\circledast}$ primer and probe sequences used to identify Vssc mutations in Aedes aegypti at codons 989, 1016 and 1534.

\begin{tabular}{|c|c|c|c|c|c|c|c|}
\hline Codon & $\begin{array}{l}\text { Loca tion in } \\
\text { Vssc gene }\end{array}$ & Forwa rd primer $5^{\prime}-3^{\prime}$ & Reverse primer $5^{\prime}-3^{\prime}$ & Probe wildtype & Probe mutant & Amino Acid & $\begin{array}{l}\text { Amplicon } \\
\text { size bp }\end{array}$ \\
\hline 989 & $\begin{array}{l}\text { P-region } \\
\text { which links } \\
\text { membrane } \\
\text { spanning } \\
\text { segments S5 } \\
\text { and S6in } \\
\text { Domain } \#\end{array}$ & 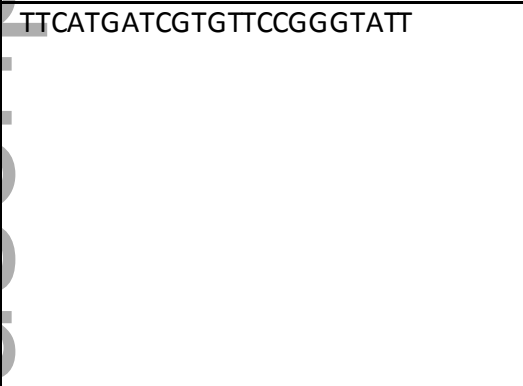 & ACGTCACCCACAAGCATACAAT & CCCACATGGATTCGAT & CCACATGGGTTCGAT & $\begin{array}{l}\text { TCC (Serine) } \\
\text { wild type, CCC } \\
\text { (Proline) } \\
\text { mutant }\end{array}$ & 53 \\
\hline 1016 & $\begin{array}{l}\text { First codon } \\
\text { of exon } 21 \\
\text { (domain II, } \\
\text { segment 6) }\end{array}$ & CGTGCTAACCGACAAATTGTTTCC & ATGAACCGAAATTGGACAAAAGCAA & AGAAAAGGTTAAGTACCTGTGCG & AAGGTTAAGTCCCTGTGCG & $\begin{array}{l}\text { GTA (Valine) } \\
\text { wildtype, GGA } \\
\text { (Glycine) } \\
\text { mutant }\end{array}$ & 52 \\
\hline 1534 & $\begin{array}{l}24^{\text {th }} \text { codon } \\
\text { of exon } 31 \\
\text { (domain III, } \\
\text { segment 6) }\end{array}$ & TCTACATGTACCTCTACTTTGTGTTCTTCA & GATGATGACACCGATGAACAGATTC & AACGACCCGAAGATGA & ACGACCCGCAGATGA & $\begin{array}{l}\text { TTC } \\
\text { (Phenylalanine) } \\
\text { wildtype, TGC } \\
\text { (Cys teine) } \\
\text { mutant }\end{array}$ & 52 \\
\hline
\end{tabular}

This article is protected by copyright. All rights reserved 
Table 2. Frequency of Vssc kdr genotypes identified in Ae. aegypti from specific countries in the Indo-Pacific region

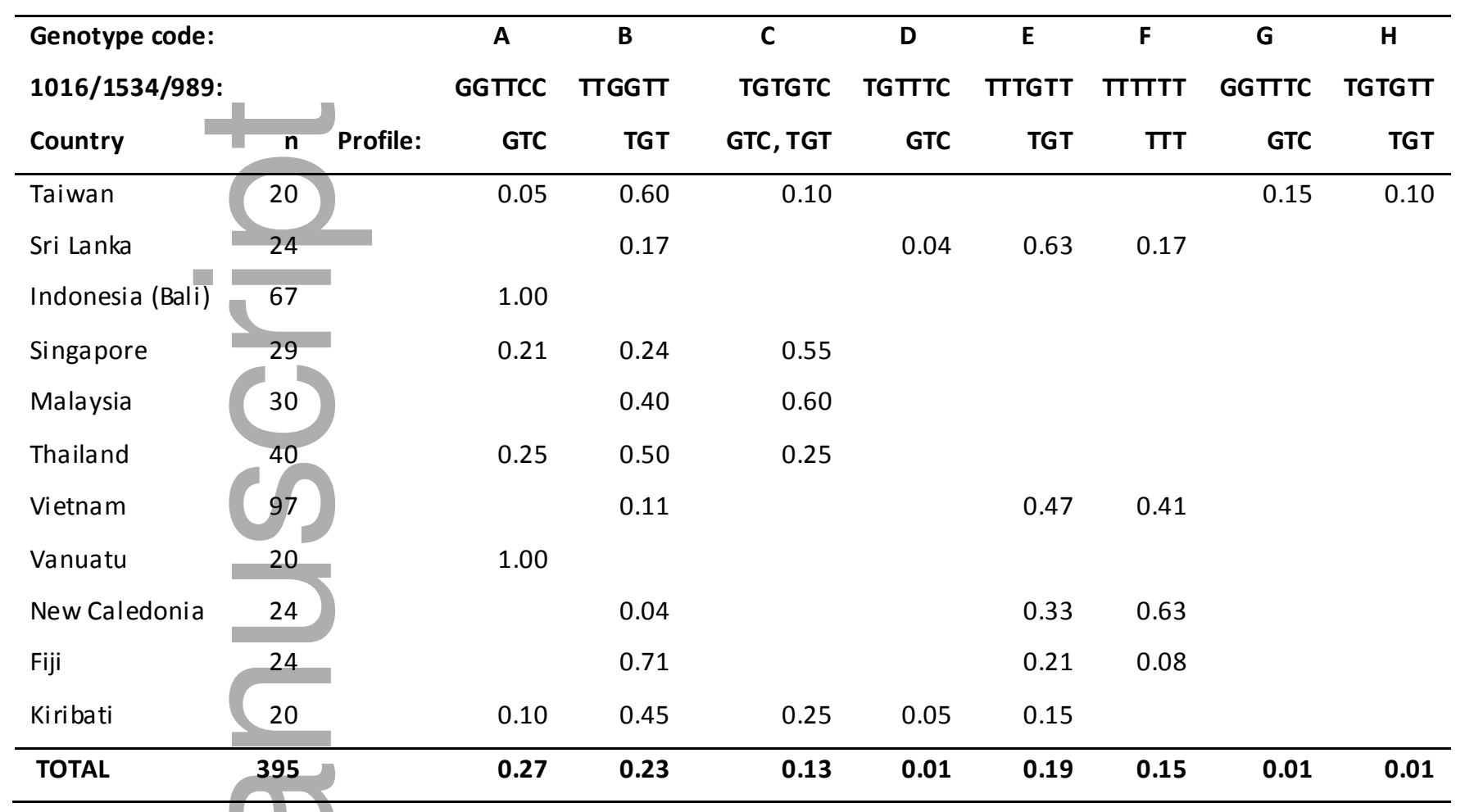

This article is protected by copyright. All rights reserved 


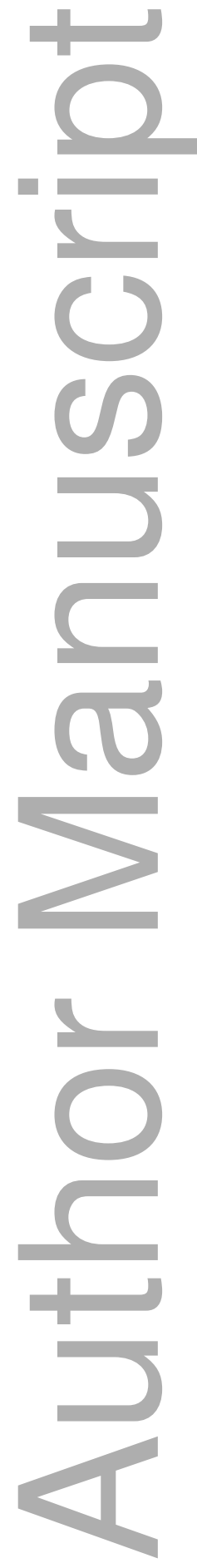

This article is protected by copyright. All rights reserved 


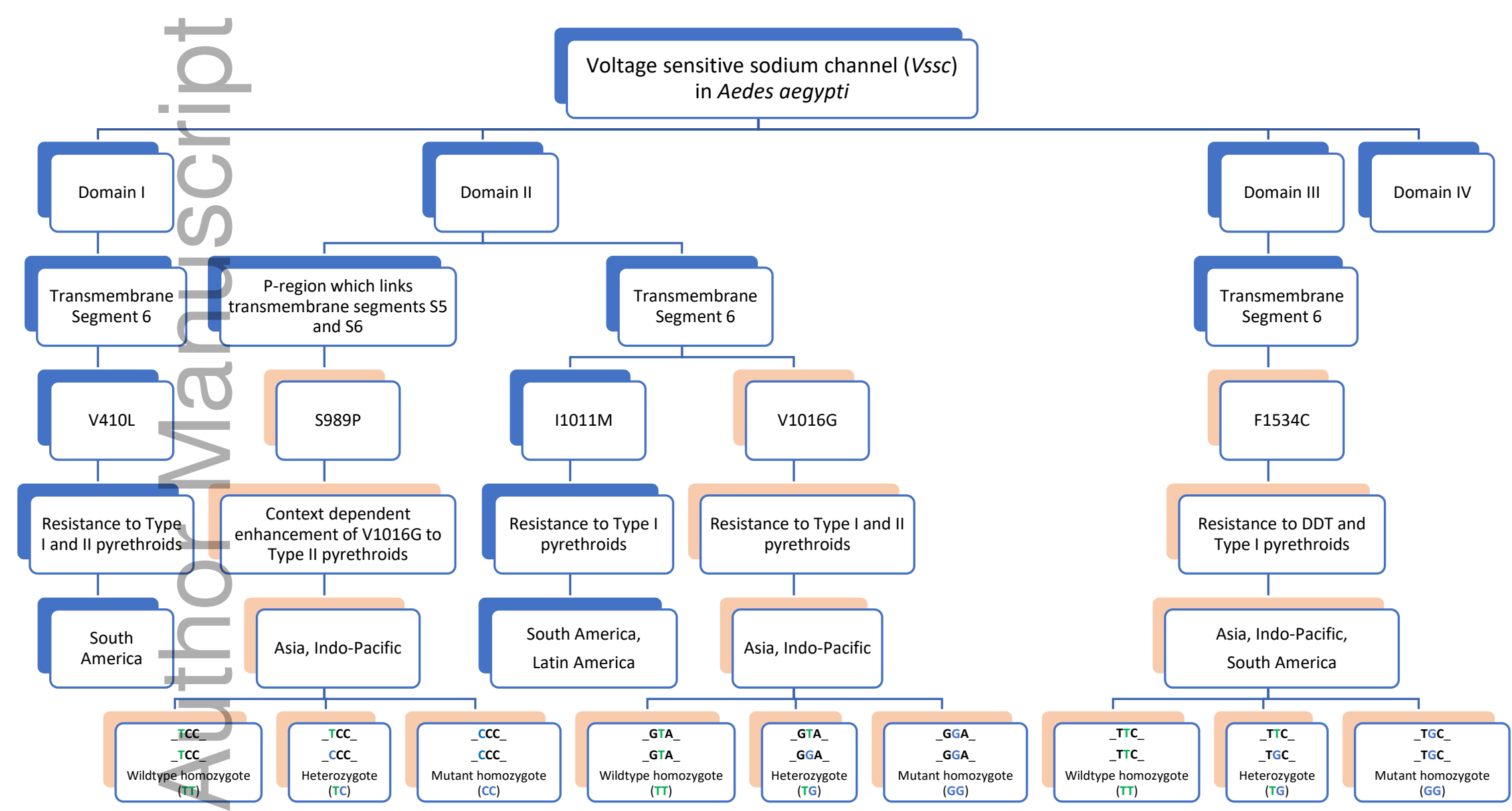

This article is protected by copyright. All rights reserved 
a.

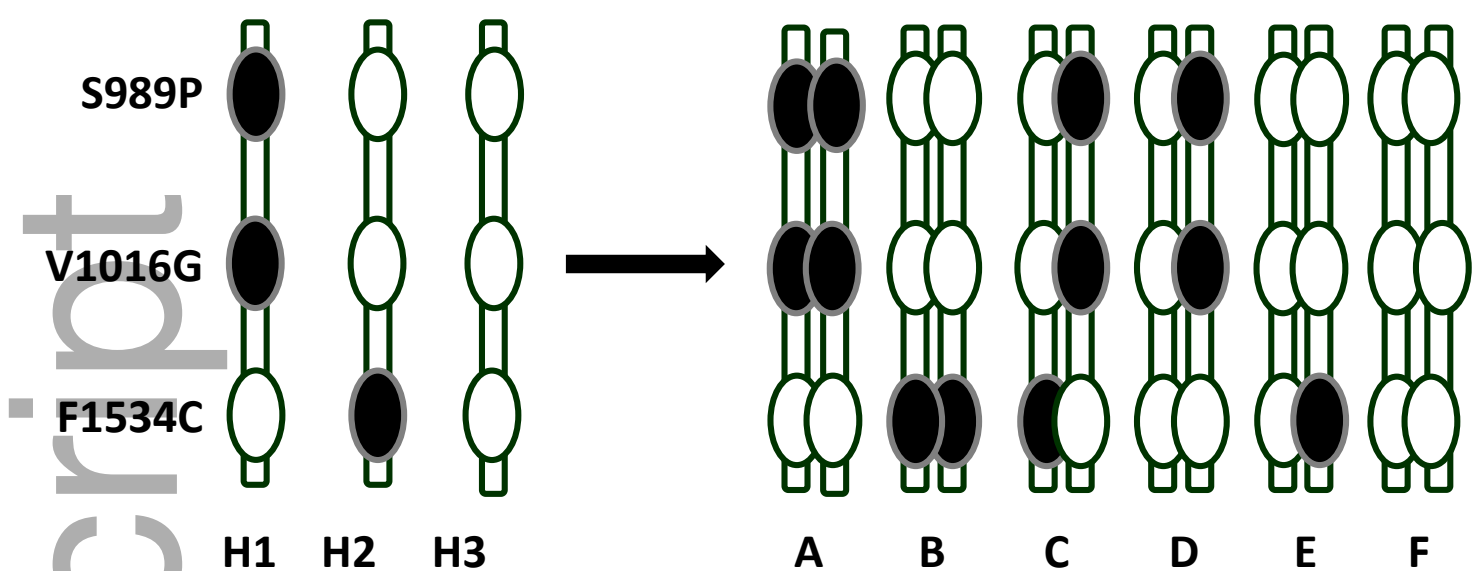

b.

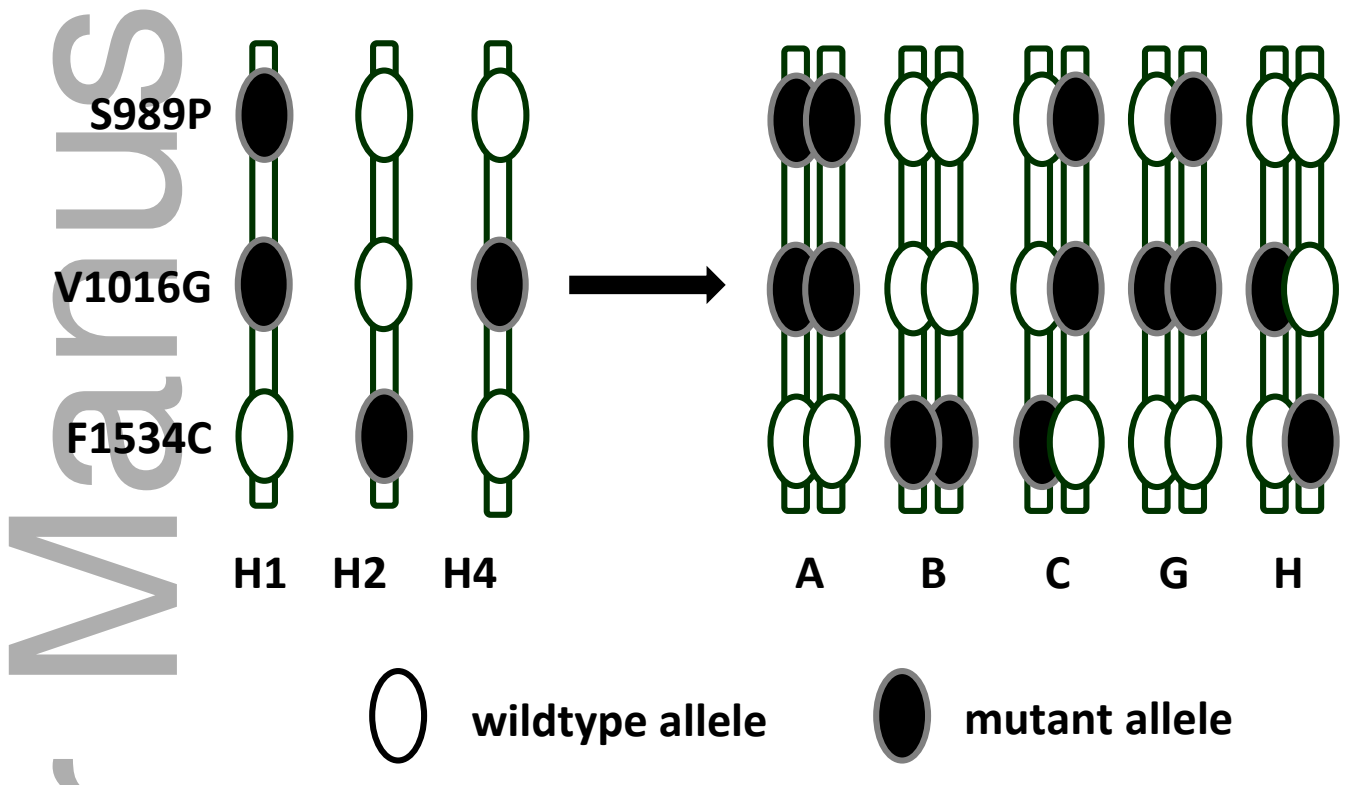

This article is protected by copyright. All rights reserved 


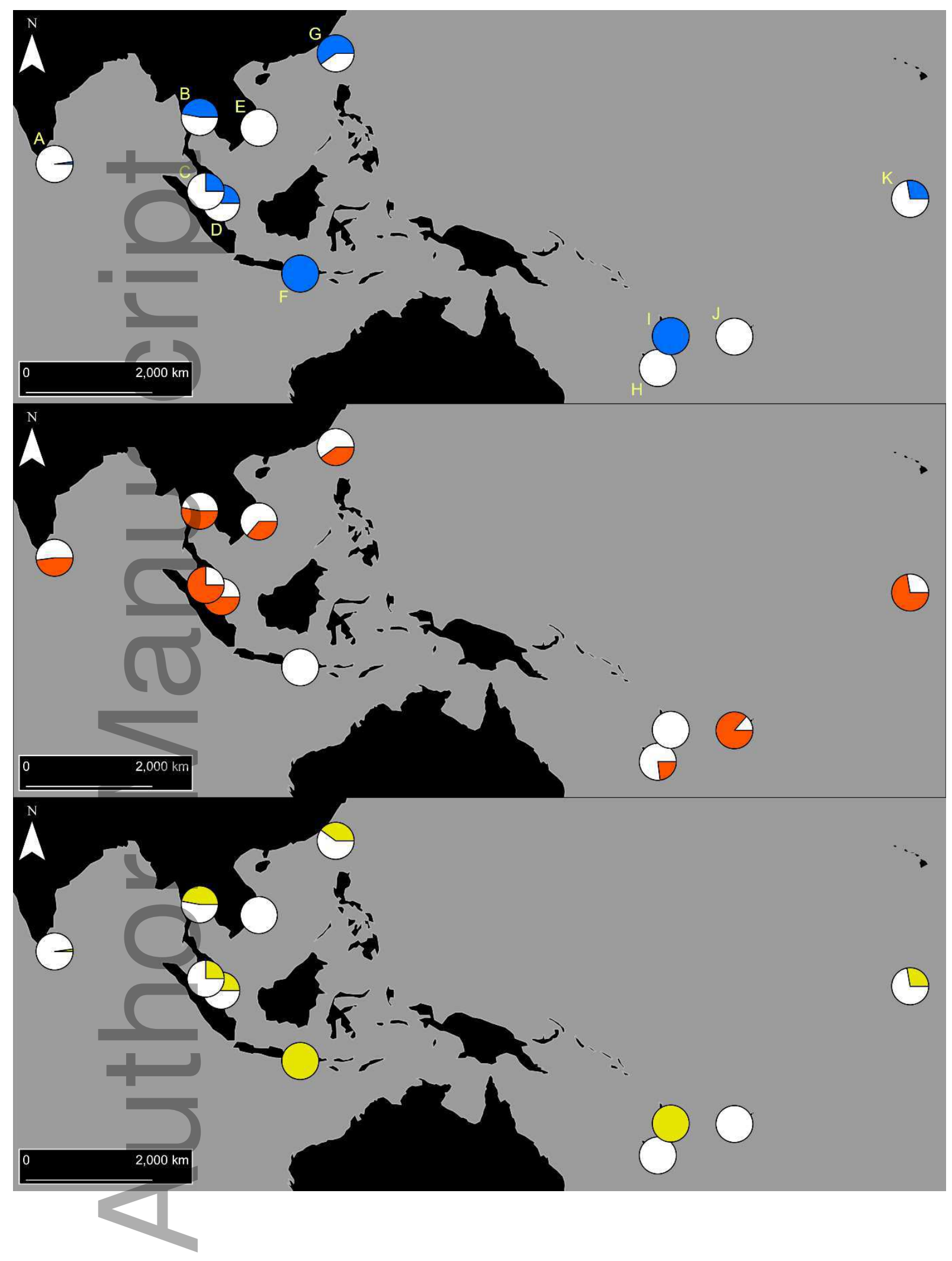

This article is protected by copyright. All rights reserved 


\section{Profile GTC}
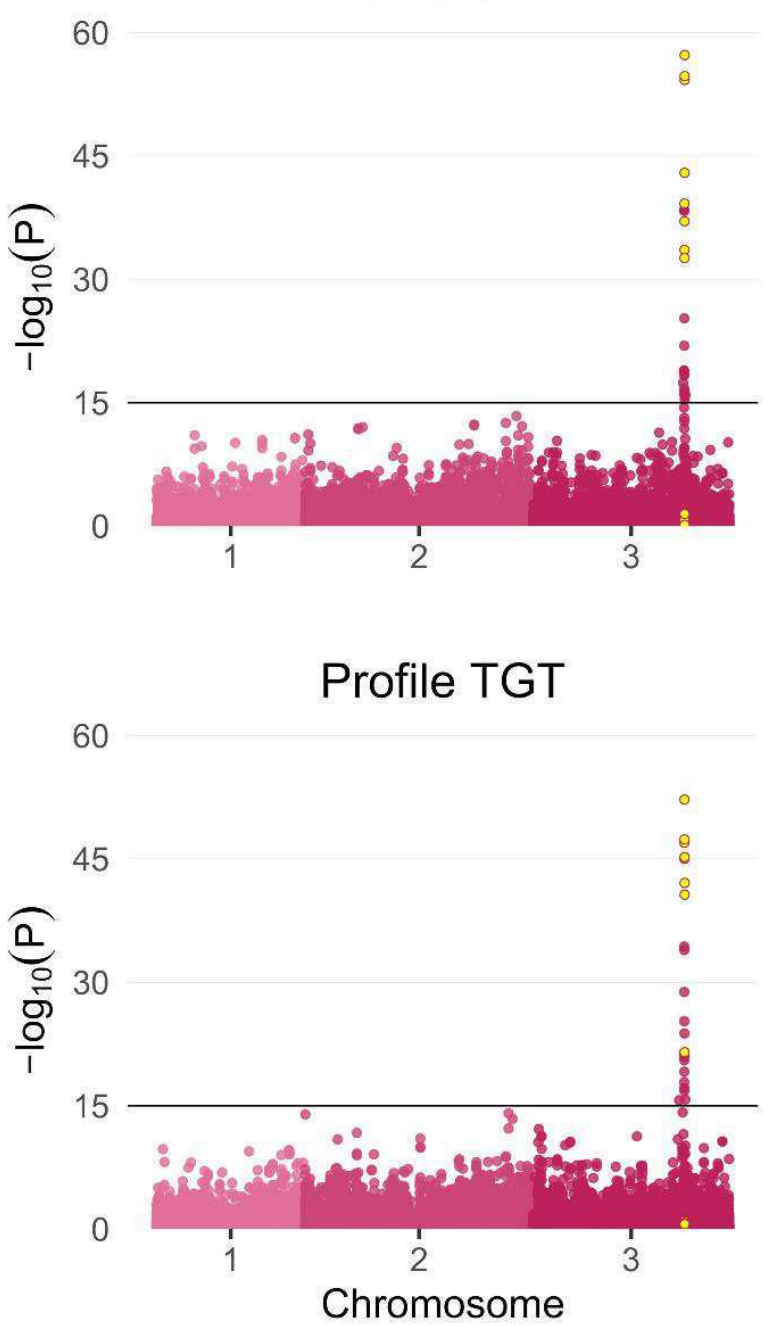

This article is protected by copyright. All rights reserved 

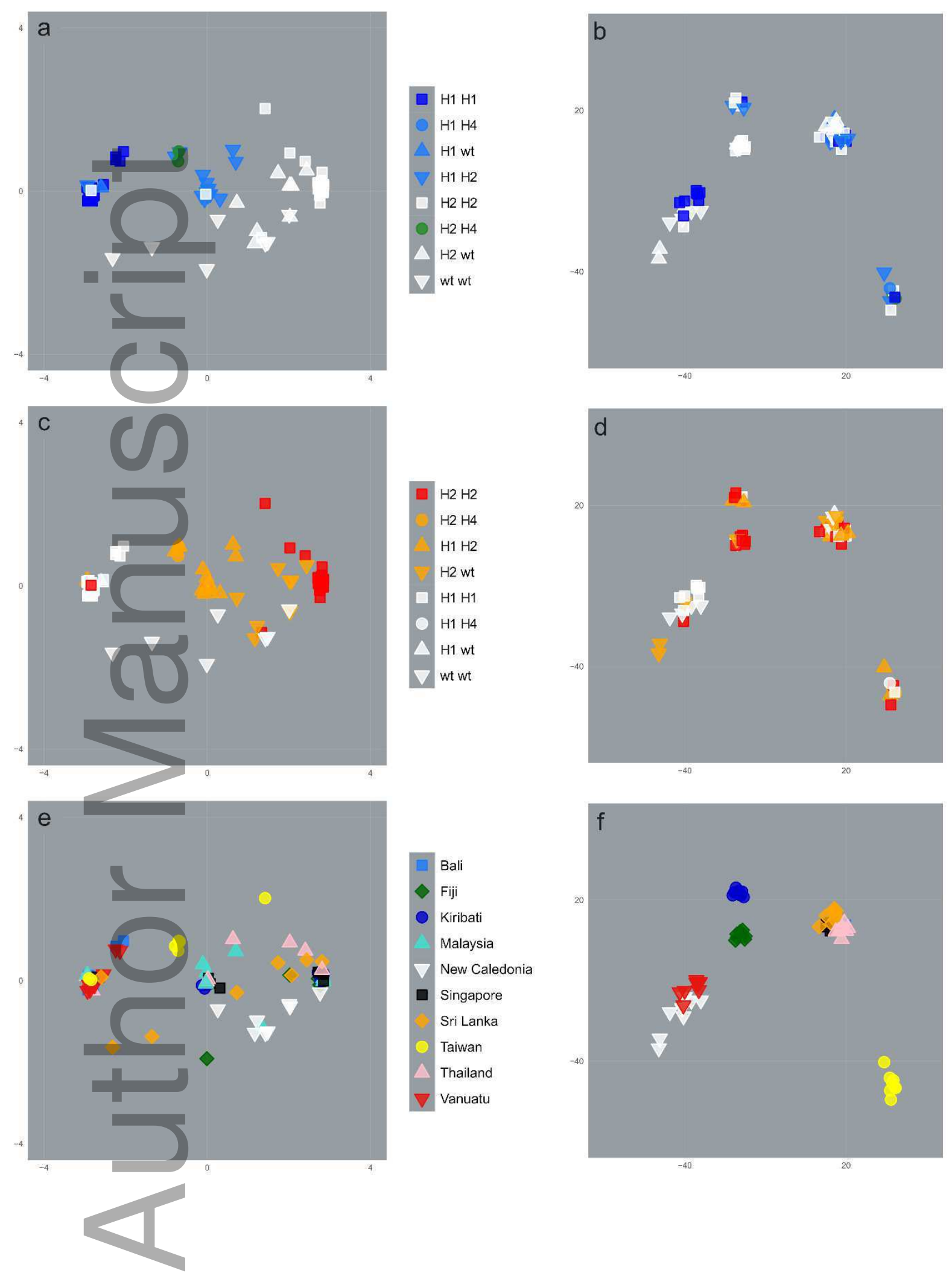

This article is protected by copyright. All rights reserved 


\section{University Library}

\section{- M M N E R VA A gateway to Melbourne's research publications}

Minerva Access is the Institutional Repository of The University of Melbourne

Author/s:

Endersby-Harshman, NM;Schmidt, TL;Chung, J;van Rooyen, A;Weeks, AR;Hoffmann, AA

Title:

Heterogeneous genetic invasions of three insecticide resistance mutations in Indo-Pacific populations of Aedes aegypti (L.)

Date:

2020-04-21

Citation:

Endersby-Harshman, N. M., Schmidt, T. L., Chung, J., van Rooyen, A., Weeks, A. R. \& Hoffmann, A. A. (2020). Heterogeneous genetic invasions of three insecticide resistance mutations in Indo-Pacific populations of Aedes aegypti (L.). MOLECULAR ECOLOGY, 29 (9), pp.1628-1641. https://doi.org/10.1111/mec.15430.

Persistent Link:

http://hdl.handle.net/11343/275670 